\title{
Wavelet-based Decomposition of Ground Acceleration for Efficient Calculation of Seismic Response in Elastoplastic Structures
}

\author{
Reza Kamgar ${ }^{1 *}$, Noorollah Majidi ${ }^{1}$, Ali Heidari ${ }^{1}$ \\ ${ }^{1}$ Department of Civil Engineering, Faculty of Technology and Engineering, Shahrekord University, 88186-34141 Shahrekord, Iran \\ * Corresponding author, e-mail: kamgar@sku.ac.ir
}

Received: 29 May 2019, Accepted: 06 November 2020, Published online: 09 December 2020

\begin{abstract}
The nonlinear dynamic analysis provides a more accurate simulation of the structural behavior against earthquakes. On the other hand, this analysis method is time-consuming since the time-step integration schemes are used to calculate the responses of the structure. Wavelet transform is also considered as one of the strong computing tools in studying the properties of the waves. The continuous wavelet transform is a time-frequency study and examines the frequency content of the waves while, the discrete wavelet transform is used to reduce sampling data and also to eliminate the noise of the waves. In this paper, the discrete and continuous wavelet transforms are used to reduce the wave sampling and therefore to reduce the required time for analysis. In this regard, eight nearand far- field earthquakes are studied. The frequency content of the earthquake is investigated by the Fourier spectrum and the continuous wavelet transform. The results show that the first five frequencies for the main earthquakes are similar to those values of earthquakes obtained by wavelet transform. Besides, it is shown that using wavelet transform for the main and decomposed earthquakes indicates that the duration of strong ground motion and the time of dominant frequency occur approximately in the same domain. Finally, it is concluded that the required calculation time reduces to about $80 \%$ with an error less than $6 \%$ when the main earthquake is decomposed by wavelet transform and the approximation waves are used in the nonlinear dynamic analysis.
\end{abstract}

Keywords

nonlinear dynamic analysis, wavelet transform, optimization, near- and far-field earthquakes

\section{Introduction}

Structural dynamic analysis is divided into linear and nonlinear analyzes. Linear analyzes are more prevalent among engineers due to the simplicity and less time computing. On the other hand, linear analyzes are approximate and do not provide accurate behavior of the structure. In contrast, the nonlinear dynamic analysis provides a precise answer to the behavior of the structure. For this reason, a nonlinear analysis is needed to obtain a more accurate response for a structure [1].

The dynamic response of a structure is determined using the spectrum and time history analysis methods [2]. Generally, for the seismic analysis of important structures [3-5] such as power plants, dams, tall buildings $[6,7]$, control vibrations $[8,9]$, and bridges, it is necessary to analyze the structure using time integration methods [2]. While this type of analysis is time-consuming, it is evident that the use of techniques that reduces the duration of dynamic analysis and the computational cost is important [10].
Time history dynamic analysis is one of the most precise methods for predicting the structural responses subjected to the earthquake loads. In the nonlinear dynamic analysis, the effects of higher modes and changes in the pattern of the inertial load are considered due to the softening of the structure. Hence, this type of analysis provides accurate behavior of the structure subjected to the earthquake load. Also, the nonlinear time integration methods are used in analyzing of structures due to the avoidance of existing approximations for the model simplification. In this case there is a higher accuracy than nonlinear static analysis. On the other hand, the nonlinear time history analysis is time-consuming due to the high volume of computing [11]. In this paper, the volume of computations related to nonlinear dynamic analysis has been reduced to over $70 \%$ for the first time by the wavelet theory (WT).

WT has been expanded for about three decades [12]. The history of the use of wavelet theory for dynamic 
analysis of the structures dates back to about twenty years ago. From a mathematical point of view, the WT provides more information about the crude wave [13]. An earthquake wave is an unpaved wave since its frequencies do not occur during the entire time of the wave, and also at each time it has different frequencies.

The linear dynamic response of the structures was calculated using a discrete wavelet transform (DWT) that was combined with the Fast Fourier Transform (FFT) method. The results showed that the required time in this method was $50 \%$ of the time used in the common analysis and its error was less than $2 \%$.

The WT is divided into two groups (i.e., continuous and discrete). Considering the nature of the earthquake acceleration, DWT is more appropriate. In [14], structures were optimized by adaptive genetic algorithm using wavelet networks to reduce the dynamic computational cost. For this purpose, after separating the high and low frequencies of the earthquake, the number of accelerated earthquake points were reduced, then the wavelet function was used as the stimulation function in the neural network. The analysis time in this method was about $10 \%$ of the time used by the neural network, while its error was less than $8 \%$.

Heidari and Majidi [15] reduced the calculations time in the earthquake displacement and velocity curves up to $93 \%$ by the discrete wavelet theory. They showed that by using the Haar wavelet function, the calculations could be reduced by an error of less than $5 \%$ [15]. In [16], the dynamic analysis of the structure was performed using a wavelet neural network. The error was negligible, while the analysis time was reduced by $90 \%$. In [17], the dynamic response of the structure up to 5 stages was estimated using wavelet transformation. The results showed that by increasing the number of each stage, the required time for the analysis becomes halved and also the error was doubled. The wavelet transform has been also used for assessing the properties of the earthquake $[18,19]$. In [20], wavelet theory and genetic algorithm methods were used for earthquake optimization. The error rate was about $2 \%$ and the time needed to optimize the structure was $15 \%$ of the time in the case the wavelet was not used. In addition, the strong ground motion parameters were calculated using wavelet transform of earthquakes. The results showed that by using a wavelet transform, one can estimate the parameters of the strong ground motion with a negligible error [18]. In [21], the non-linear response spectrum of the structures was calculated by using the wavelet transform. Results showed that the error was less than $10 \%$ while the wavelet transform has been used. Optimization of structures using meta-heuristic optimization methods and wavelet transform is also an interesting issue that has attracted the researchers [22].

In this context, a new dynamic fuzzy wavelet neuro-emulator model was proposed by Jiang and Adeli [23] to control the dynamic responses of three-dimensional building structures. Blachowski and Pnevmatikos [24] proposed a new method in the form of a neural network to attenuate the vibration of the structures subjected to an earthquake.

In this paper, for the first time, the wavelet theory is used for nonlinear dynamic analysis of structures. The aim is to reduce the computational volume using a discrete wavelet transform. To investigate the proposed method, eight near and far field earthquakes are selected from FEMA-P695 [25]. Four earthquakes are known as farfield and the others are categorized as near-field earthquakes. In this paper, each earthquake is first filtered up to 5 stages by wavelet transform. At each stage of the filter, two waves, approximations and details are obtained. Due to the small amount of details in the information, this wave is neglected [15]. The next step is to study the frequency content of the earthquake using the Fourier spectrum and the continuous wavelet transform. At the end, the nonlinear dynamic response of a seven-story structure is studied. For this purpose, the Mallat and Shensa methods are used in the wavelet theory to analyze the dynamic response of the structure. The results showed that the analysis time is reduced by about $80 \%$ while the error was about up to $6 \%$.

\section{Wavelet transform}

Two concepts are important in the wavelet transform: mother functions and scale [26]. The mother functions are used in the continuous wavelet transform and the scale functions are used in the discrete wavelet transform to separate the frequencies. The mother functions and wavelet scale are shown by $\psi$ and $\varphi$, respectively. In this paper, the wavelet transform is used discretely and continuously. Therefore, both mathematical principles are discussed below. A wavelet is an alternate, real or imaginary function with a mean of zero and a finite length. Its space is defined as $\psi(t) \in L^{2}(R)$. The $\psi(t)$ function is called the mother wavelet, and $L^{2}(R)$ represents the measurable Hilbert space of integrable quadrilateral functions. The $\psi(t)$ function in both the domain and space frequency is used to create a family of wavelets and is shown as follows:

$\psi_{u, s}(x)=\frac{1}{\sqrt{s}} \psi\left(\frac{x-u}{s}\right)$. 
In this case, real numbers $s$ and $u$ are scale parameters and wavelet transforms. For a signal whose target is a wavelet filter, the coordinate space $f(t) \in L^{2}(R)$ is considered. In addition, $t$ specifies the spatial coordinates. The continuous wavelet transform is equal to the internal multiplication of the signal function (wave) in the wavelet function.

$$
W f(u, s)=f, \psi_{u, s}=\frac{1}{\sqrt{s}} \int_{-\infty}^{+\infty} f(t) \psi\left(\frac{t-u}{s}\right) d t,
$$

where, $W f(u, s)$ is called the wavelet coefficient for $\psi_{u, s}(t)$. The integral of the wavelet transform can be written as follows:

$$
\begin{aligned}
W f(u, s) & =\frac{1}{\sqrt{s}} \int_{-\infty}^{+\infty} f(t) \psi\left(\frac{-(u-t)}{s}\right) d x \\
& =\frac{1}{\sqrt{s}} f^{*} \psi\left(\frac{-u}{s}\right)=f^{*} \bar{\psi}_{s}(u),
\end{aligned}
$$

where, $\bar{\psi}_{s}(x)=1 / \sqrt{s} \psi(x / s)$.

It should be noted that an important issue to wavelet-based structural analysis is selecting the appropriate so-called mother wavelet. Some functions can generate an accelerogram whose response spectrum is compatible with that of the main earthquake $[16,18,19]$. Basu and Gupta [27] proposed a new theory based on the wavelet to predict the seismic responses of a single degree of freedom system subjected to the earthquake load. Also, Suarez and Montejo [28] used the wavelet transform to produce the artificial earthquake. In this paper, the Haar mother wavelet is used. The good performance of this mother wavelet has been proved in $[16,18,19,29]$.

The mother function of the Haar wavelet and its scale function are defined as follows:

$$
\begin{gathered}
\psi(t)=\left\{\begin{array}{ll}
1 & 0 \leq t<0.5 \\
-1 & 0.5 \leq t<1 \\
0 & \text { otherwise }
\end{array},\right. \\
\varphi(t)=\left\{\begin{array}{ll}
1 & 0 \leq t \leq 1 \\
0 & \text { otherwise }
\end{array} .\right.
\end{gathered}
$$

In the wavelet transform, there are two parameters: scale and transition. The scale parameter is similar to the scale in the maps. Selecting a small value for the scale parameter shows the details while using a large value corresponds to the lack of detail for the wave. Therefore, the scale like a mathematical function compresses or expands a wave. The large scale corresponds to the opening of the wave and the small scales make the wave to compress. The low frequency (large scale) corresponds to the general information of wave and frequency. The high frequencies for a long time are unscathed from the wave, while there are low frequencies throughout the wave. In the continuous wavelet transform, the transmission and scale parameters are continuously changed that this leads to the increase of the computational cost [30]. In the case of discrete wavelet transform, transmission and scale that are considered discretely. Another type of wavelet transform is called wavelet fracture transformation [31]. In the high scales (low frequencies), the sampling rate of the time curve points can be reduced in accordance with the Nyquist frequency and therefore, the computational volume reduces. Nyquist sampling is the minimum allowed sampling rate of a continuous wave that can be reconstructed. For a wave with a specific length (number of points), it is possible to remove the high frequencies of the main wave to obtain the approximate wave using the lower filters while in the case of a high pass filter, the low frequencies can be removed and the wave details can be obtained. With the simultaneous effect of these two filters on the wave, it can be divided into two parts with high and low frequencies. The approximation and detailed waves are shown as $A_{j}$ and $D_{j}$, respectively for each step. However, the approximation and detailed waves are obtained from the main wave with the number of points equal to the main wave in each stage using these filters. To overcome this problem, a sample reduction is used [32]. In the reduction of sampling points, one is preserved and the other will be deleted. Therefore, the number of points per wave is approximately half of the main wave points (see Fig. 1). After this step, the number of wave points can still be reduced. Because the maximum wave energy is in its approximation and the shape of this part is more similar to the main wave, then the filtering operation for this part is carried out and the wave is divided into two waves. The number of points in each of these waves is about half the number of points in input wave. Although, from a theoretical point of view, this transform can be done for a large number, it should be noted that the approximate part should be similar to the main earthquake for the nonlinear dynamic analysis. In addition, in each

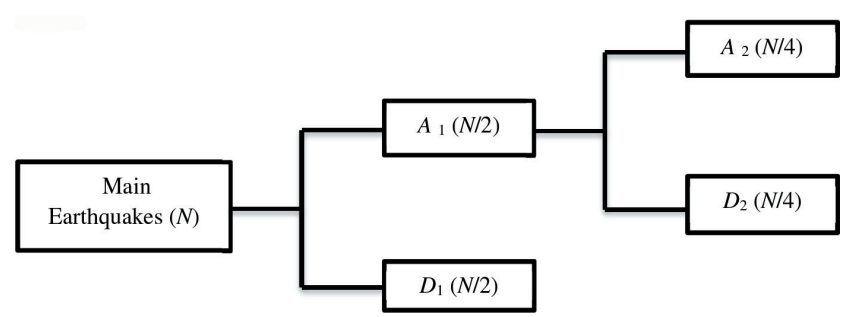

Fig. 1 Down-sampling method algorithm up to two steps 
stage, the value of the time step increases that should be considered. It should be noted that the rapid conversion of the wavelet acts like a filter bank $[32,33]$.

In this method, approximate waves $\left(A_{j}\right)$ and detail wave $\left(D_{j}\right)$ are obtained as follows [32].

$$
\begin{aligned}
& A_{j}=a p_{j, k}=\sum_{n} s(n) h_{j}^{*}\left(n-2^{j} k\right), \\
& D_{j}=d e_{j, k}=\sum_{n} s(n) g_{j}^{*}\left(n-2^{j} k\right),
\end{aligned}
$$

where, $h_{j}$ is low pass filter and $g_{j}$ is high pass filter. The $h$ and $g$ filters are also calculated from step $j$ to the step $j+1$ as follows [33].

$$
\begin{aligned}
& g_{1}(n)=g(n) \\
& h_{1}(n)=h(n) \\
& g_{j+1}(n)=\sum_{k} g_{j}(k) g(n-2 k) \\
& h_{j+1}(n)=\sum_{k} h_{j}(k) g(n-2 k)
\end{aligned}
$$

These equations indicate that this method is similar to the theory of filters and that the rapid wavelet transform corresponds to the filtering of the filter bank. In addition, the filters that are used in the inverse wavelet transformation are shown as follows:

$\tilde{h}_{j}\left(n-2^{j} k\right)=2^{-0.5 j} \tilde{\psi}\left(2^{-j}\left(t-2^{j} k\right)\right)$,

$\tilde{g}_{j}\left(n-2^{j} k\right)=2^{-0.5 j} \tilde{\varphi}\left(2^{-j}\left(t-2^{j} k\right)\right)$.

The $\psi$ and $\varphi$ functions are the mother and scale functions. With $\tilde{h}$ and $\tilde{g}$, the values and the main wave can be reconstructed using the following relationship.

$$
\begin{aligned}
s(n) & =\sum_{j=1}^{J} \sum_{k} a p_{j, k} \tilde{h}_{j}\left(n-2^{j} k\right) \\
& +\sum_{j=1}^{J} \sum_{k} d e_{j, k} \tilde{g}_{j}\left(n-2^{j} k\right)
\end{aligned}
$$

\section{Equations of motion}

In this section, a multi-degree-of-freedom structure is considered subjected to the horizontal acceleration of earthquake $\left(\ddot{x}_{g}\right)$. The dynamic equation of motion for the assumed system can be expressed as follows:

$$
[\mathbf{M}]\{\ddot{\boldsymbol{x}}(t)\}+[\mathbf{C}]\{\dot{\boldsymbol{x}}(t)\}+f_{s}\{\boldsymbol{x}(t), \dot{\boldsymbol{x}}(t)\}=-[\mathbf{M}]\{\boldsymbol{l}\} \ddot{x}_{g}(t),
$$

where $[\boldsymbol{C}],[\boldsymbol{M}],\{\boldsymbol{x}\},\{\dot{\boldsymbol{x}}\},\{\ddot{\boldsymbol{x}}\}$ and $\{\boldsymbol{l}\}$ show the damping matrix, mass matrix, displacement vector, velocity vector, acceleration vector and influence vector, respectively. Also, $f_{s}\{\boldsymbol{x}(t), \dot{\boldsymbol{x}}(t)\}$ shows the relation between lateral force and displacement for a nonlinear system. Assuming that the damping matrix is classic and obeys from the Rayleigh damping. Therefore, the numerical solution for the equations of motion in Eq. (14) can be obtained using various numerical methods such as Newmark Method [34]. It should be noted that in this paper, the damping ratio for all modes is considered to be equal to 0.05 .

\section{Non-linear material specification}

In this paper, the OpenSees software [35] is used for nonlinear dynamic analysis of the structure. In this regard, one of the default nonlinear material (Steel 01) is used. The stress-strain curve of steel 01 is modeled as has been shown in Fig. 2. The steel 01 model has kinematic hardening behavior and optional isotropic hardening behavior. As shown in Fig. 2(b), it can be seen that, in the case of non-isotropic hardening, the area under the hysteresis loops remains almost constant. In this paper, isotropic hardening behavior is neglected.

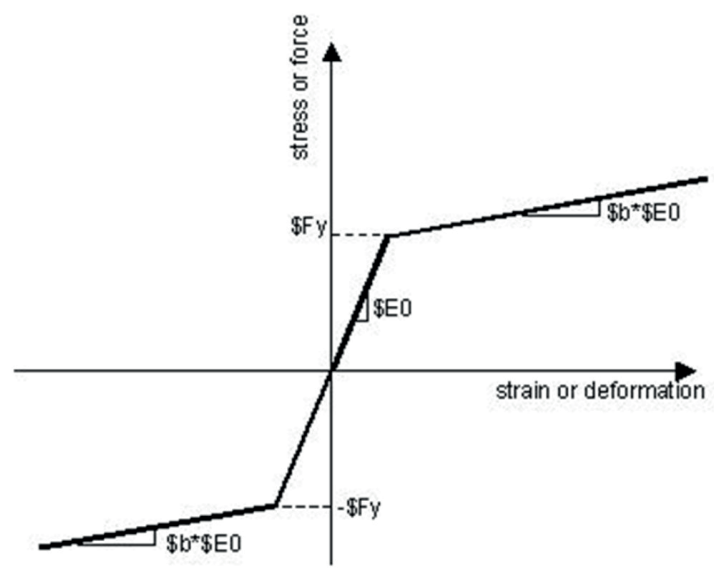

(a)

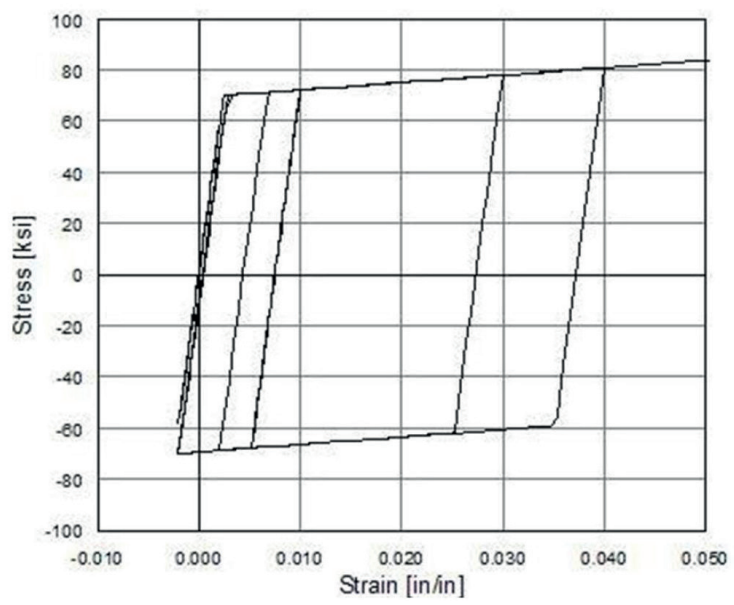

(b)

Fig. 2 (a) Stress-strain curve of steel 01 without isotropic hardening, (b) Hysteresis curve of steel 01 without isotropic hardening [35] 
In Fig. 2(a), the parameters $F_{y}, E_{0}$ and $b$ are shown the yield stress, the initial elasticity modulus, and the strain hardening ratio, respectively. In this paper, these parameters are considered to be $2.354 \times 10^{8}\left(\mathrm{~N} / \mathrm{m}^{2}\right), 2 \times 10^{11}\left(\mathrm{~N} / \mathrm{m}^{2}\right)$ and, 0.02 respectively. In addition, the nonlinear beam-column element [35] is used to model the beam and column sections.

\section{Selected earthquakes}

In this section, a set of suitable earthquakes are selected in order to do the nonlinear dynamic analysis of the structure. According to Chandler's classification [36], the accelerograms are divided into three sets based on their (PGA/PGV) ratios where PGA and PGV show the peak ground acceleration and velocity of the earthquake, respectively. In this classification, records with $\mathrm{PGA} / \mathrm{PGV}<0.8 \mathrm{~g} /(\mathrm{m} / \mathrm{sec})$ are classified in low $\mathrm{PGA} / \mathrm{PGV}$ range, whereas those with $\mathrm{PGA} / \mathrm{PGV}>1.2 \mathrm{~g} /(\mathrm{m} / \mathrm{sec})$ are classified as having high (PGA/PGV) ratios. Records with (PGA/PGV) between 0.8 and $1.2 \mathrm{~g} /(\mathrm{m} / \mathrm{sec})$ are classified as the intermediate (PGA/PGV) range [4, 6, 36, 37]. In this paper, eight-earthquakes have been used to examine the proposed method. In this regard, four earthquakes are categorized as far-field and the others are known as near-field earthquakes [25]. In Table 1, the characteristics of the selected earthquakes for far- and near-field earthquakes are shown respectively. As it has been shown in Table 1, all three sets based on the Chandler's classification have been selected.

Firstly, the acceleration response spectrum of a nearand a far-field earthquake has been shown in Fig. 3 to show the performance of the Harr mother wavelet in finding the responses of the structures. This figure shows proper compliance between the response spectrum calculated from the main earthquake and the earthquake obtained from the wavelet decomposition by Haar mother wavelet.

Based on the above-mentioned statement for the discrete wavelet transform (DWT), the time history of acceleration for the main earthquakes and the detail signal obtained

\section{Near-field earthquakes}

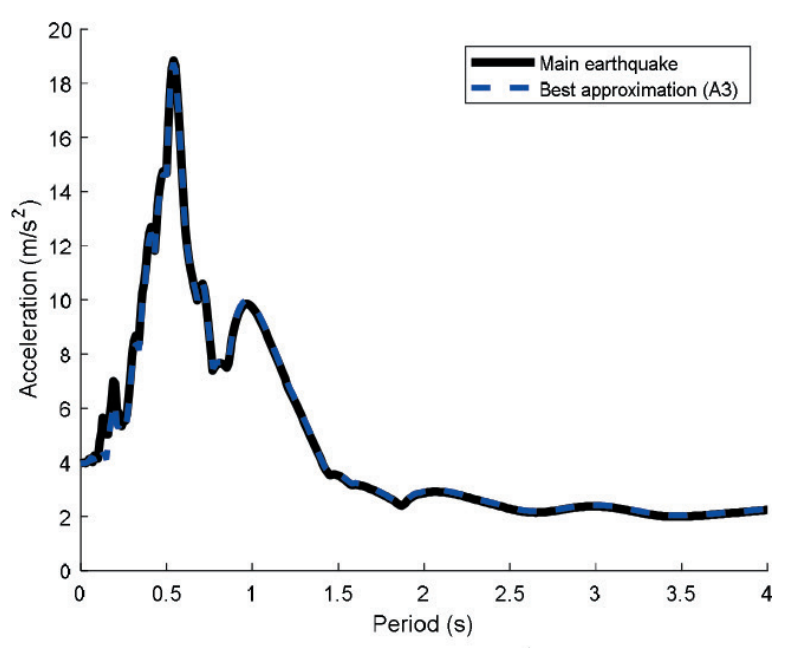

(a)

\section{Far-field earthquakes}

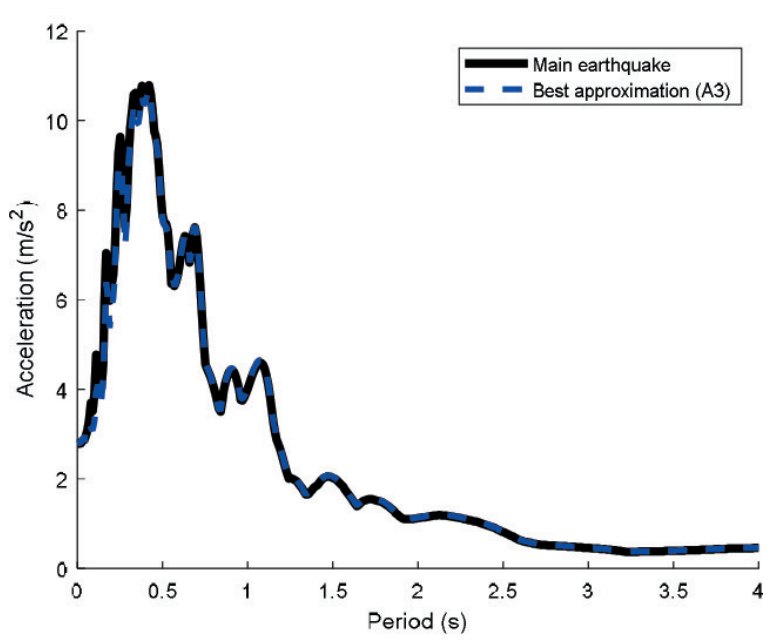

(b)

Fig. 3 Acceleration response spectrum (a) Duze earthquake, (b) Landers earthquake

from DWT are plotted in Fig. 4. As it can be seen, the wavelet filters have a good overlap with the main selected earthquakes.

Table 1 Specifications of selected earthquakes

\begin{tabular}{|c|c|c|c|c|c|c|c|}
\hline Type & Earthquake & PGA $\left(\mathrm{m} / \mathrm{s}^{2}\right)$ & PGV $(\mathrm{cm} / \mathrm{s})$ & PGD $(\mathrm{cm})$ & Time Step & PGA/PGV (g. sec/m) & Record \\
\hline \multirow{4}{*}{ Near } & Duzce & 3.96 & 71.15 & 49.69 & 0.005 & 0.57 & 5177 \\
\hline & Gazli & 8.47 & 67.65 & 20.71 & 0.0066 & 1.28 & 1984 \\
\hline & Imperial Valley & 2.64 & 24.80 & 9.29 & 0.01 & 1.08 & 5159 \\
\hline & Irpinia & 2.22 & 36.98 & 13.12 & 0.0024 & 0.61 & 16392 \\
\hline \multirow{4}{*}{ Far } & Landers & 2.78 & 35.40 & 29.92 & 0.005 & 0.80 & 7180 \\
\hline & Chi-Chi & 3.33 & 65.00 & 34.93 & 0.005 & 0.52 & 18000 \\
\hline & Superstition & 3.50 & 48.07 & 19.27 & 0.005 & 0.74 & 11999 \\
\hline & Northridge & 4.34 & 59.29 & 15.48 & 0.01 & 0.75 & 2999 \\
\hline
\end{tabular}


Near-field earthquakes

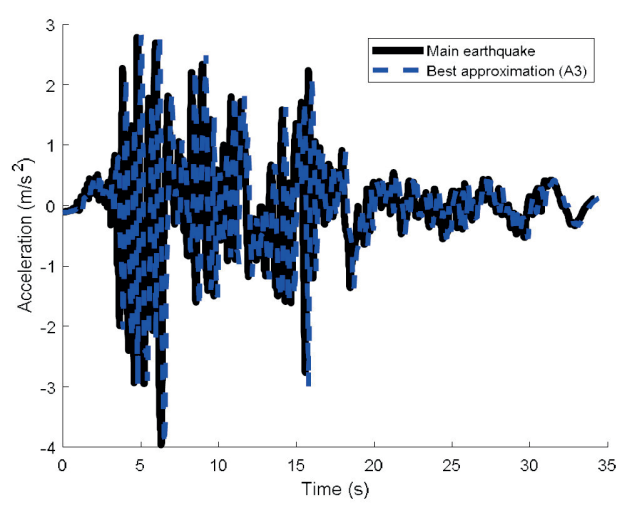

(a) Duze earthquake

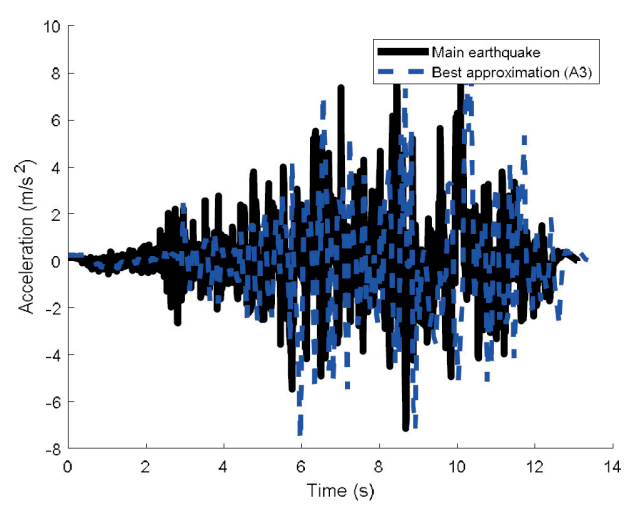

(c) Gazli earthquake

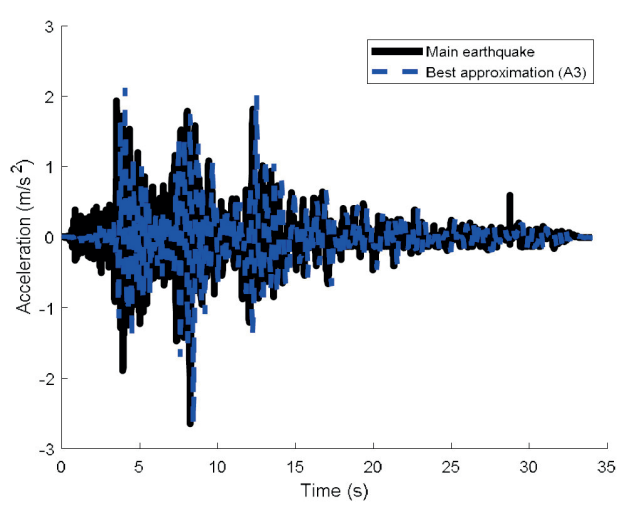

(e) Imperial Valley earthquake

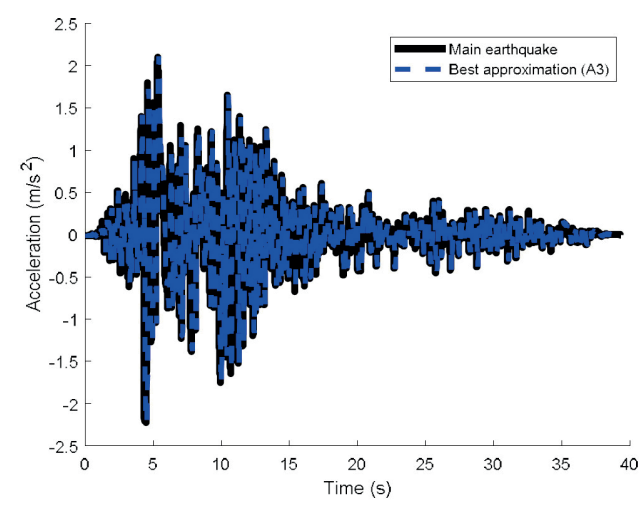

(g) Irpinia earthquake
Far-field earthquakes

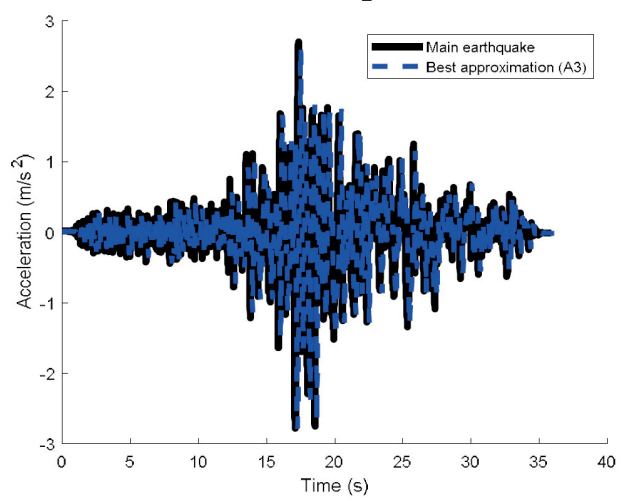

(b) Landers earthquake

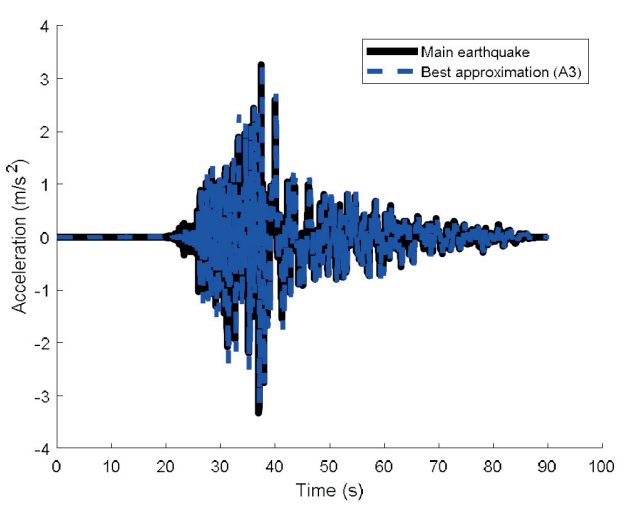

(d) Chi-Chi earthquake

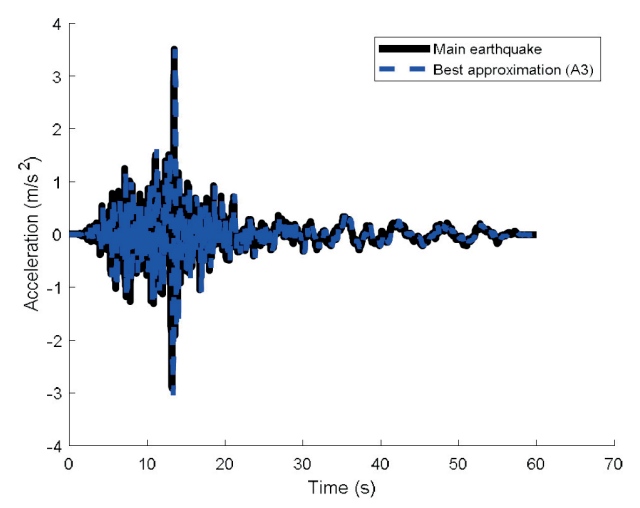

(f) Superstition earthquake

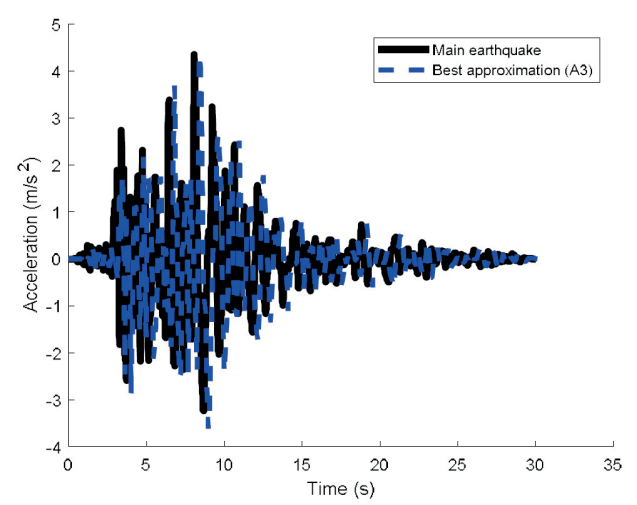

(h) Northridge earthquake

Fig. 4 The wavelet decomposition for the main earthquakes 


\section{Dominant frequencies of waves}

In this section, ten dominant frequencies of selected earthquakes (see Table 1) and wavelet filters are investigated. Fig. 5 shows the Fourier spectrum of each wave. The purpose of this work is to study the frequency of waves. In Fig. 5, the horizontal and vertical axis include the frequency number and the frequency value, respectively.

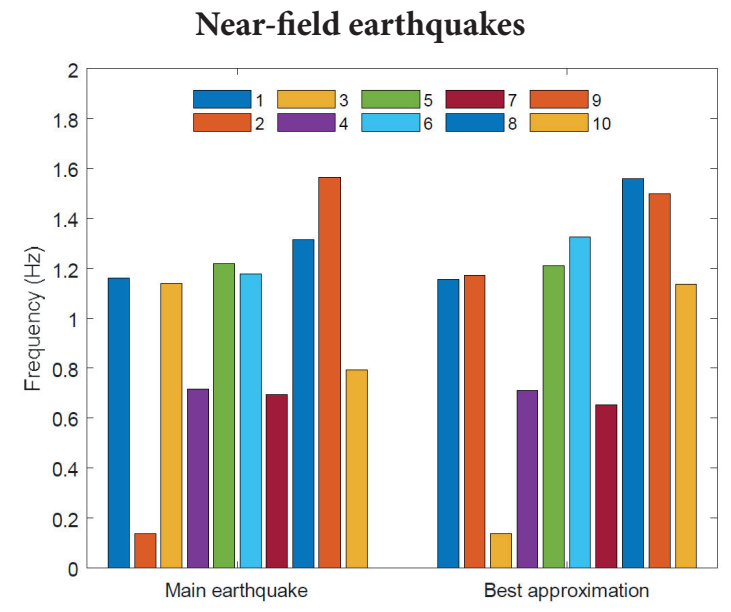

(a) Duze earthquake

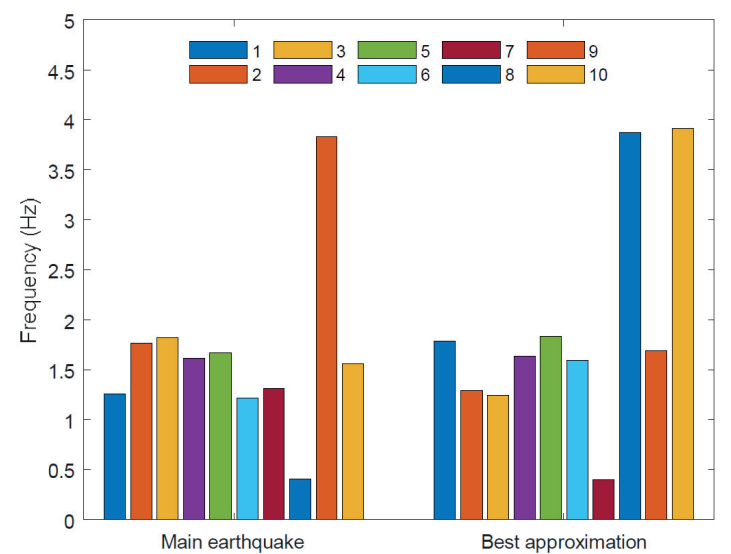

(c) Gazli earthquake

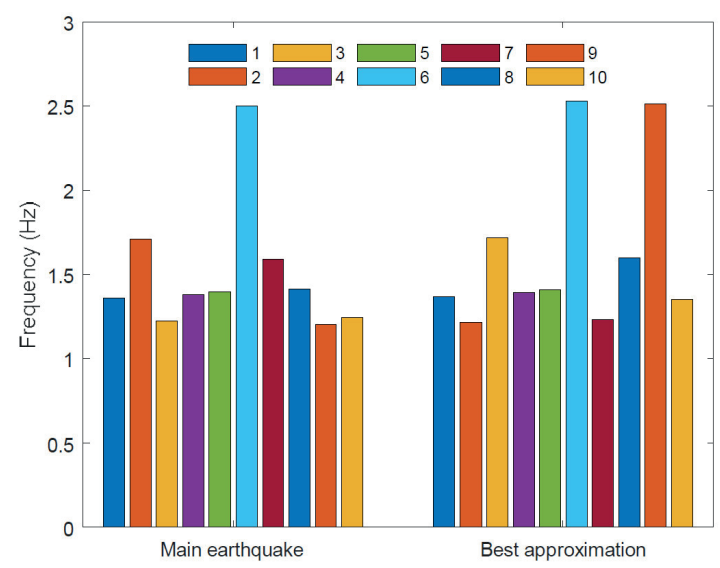

(e) Imperial Valley earthquake
Considering Fig. 5, it can be concluded that the first five frequencies for the main earthquakes are similar to those values of earthquakes obtained by WT. Therefore, it can be concluded that the $A_{2}$ wave, with a reduction of $75 \%$ of the calculations, is almost effective for all earthquakes. In addition, it can also be concluded that the values of error for the far-field earthquakes is less than near-field earthquakes.

\section{Far-field earthquakes}

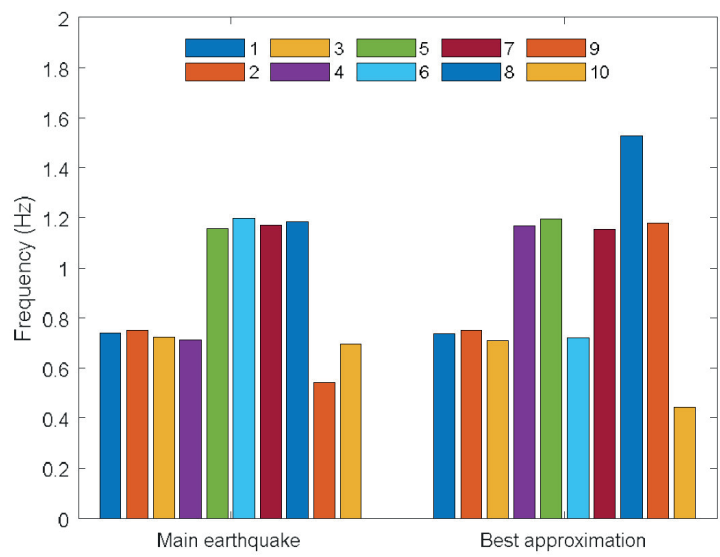

(b) Landers earthquake

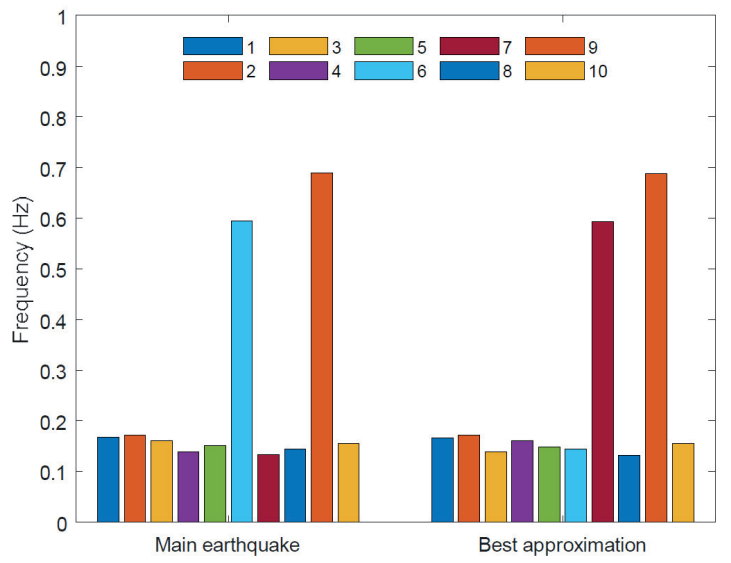

(d) Chi-Chi earthquake

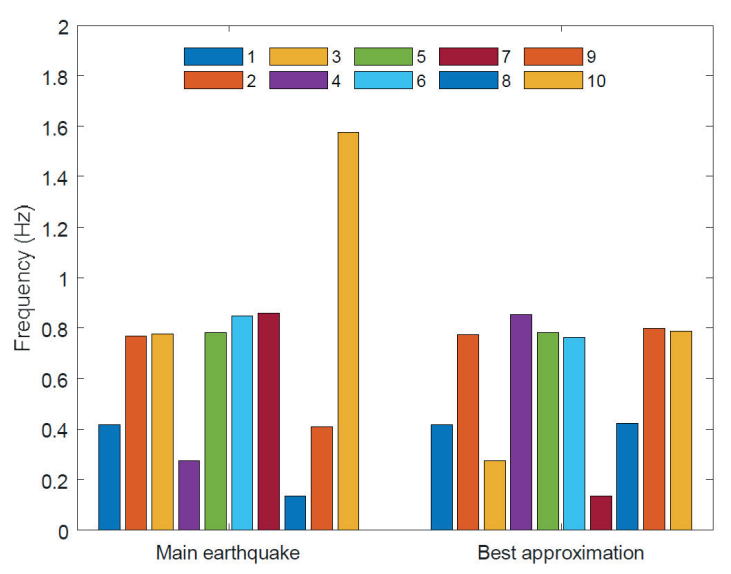

(f) Superstition earthquake

Fig. 5 (a-f) Dominant frequencies for the main earthquakes 


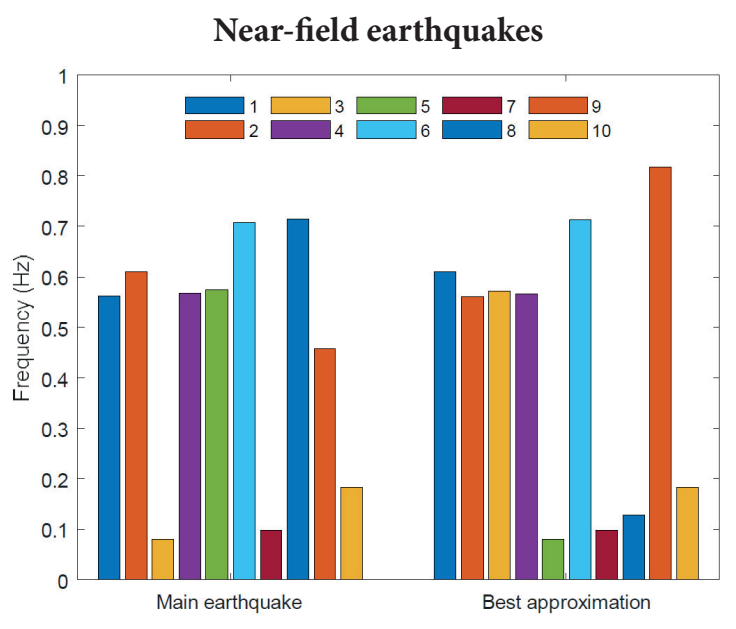

(g) Irpinia earthquake

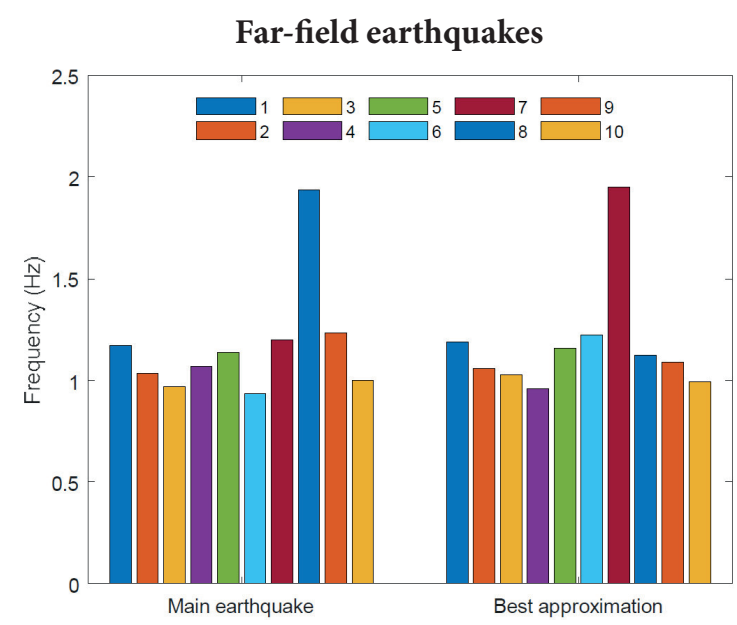

(h) Northridge earthquake

Fig. 5 (g-h) Dominant frequencies for the main earthquakes

\section{Studying the time-frequency diagram for the selected earthquakes}

In this section, using the definition of discrete and continuous wavelet transforms, the time-frequency diagram of the earthquakes is plotted in Fig. 6. It should be noted that the purpose of these graphs is not to obtain the dominant frequencies, but the purpose of these graphs is to determine the time of dominant frequencies (a time range that most frequencies occur in it). In fact, based on Figs. 4 and 6, it can be concluded that for all studied earthquakes, the time of dominant frequencies is similar in the Figs. 4 and 6. For example, in Figs. 4(b) and 6(b), the time of strong ground motion and the time of dominant frequencies are similar. In Fig. 6, the use of the wavelet transform has eliminated high frequencies, which has had little effect on the response of the structure (see Figs. 3-4). Still, it has dramatically reduced the amount of computational cost.

\section{A Numerical example for studying the effect of dwt on the nonlinear dynamic analysis}

\subsection{Roof displacement}

In this section, a non-linear time history analysis of a seven-story structure is discussed. The geometric characteristics of the structure and the used sections for the beams and columns are shown in Fig. 7

In Fig. 8, the response of reference node (see Fig. 7) is shown for various earthquakes. With reference to Fig. 8, it can be seen that $A_{3}$ is the best alternative to the main earthquake in all studied earthquakes for computing the displacement of the reference node that reduces the computational costs over $85 \%$ in the nonlinear dynamic analysis.
The results for the maximum displacement of the reference node are shown In Tables 2 and 3. Considering these tables, it can be concluded that except for Gazli and Chi-Chi earthquakes, in all earthquake $A_{3}$ wave is the best alternate earthquake wave by reducing the computational costs to about $85 \%$. Also, in all earthquakes, $A_{1}$ wave is the best alternate earthquake wave by reducing the calculations by $50 \%$.

\subsection{Base shear}

In Fig. 9, the time history of base shear is shown for various earthquakes. With reference to Fig. 9, it can be seen that $A_{3}$ in all studied earthquakes is the best alternative to the main earthquake by reducing the computational costs up to $85 \%$.

The results of the max base shear are shown in Tables 4-5. With regard to the results of these tables, it can be concluded that except for the Gazli and Chi-Chi earthquakes, in all earthquakes, $A_{3}$ wave is the best alternative wave for the earthquake by reducing the computational costs to about $85 \%$. Also, in all earthquakes, $A_{1}$ wave is the best alternate earthquake wave by reducing the calculations to about $50 \%$.

\subsection{Drift ratio}

The drift ratio of the studied building subjected to the different earthquakes is shown In Fig. 10. With reference to Fig. 10, it can be seen that $A_{3}$ is the best alternative to the main earthquake for all earthquakes by reducing the computational costs to about $85 \%$. 
Near-field earthquakes

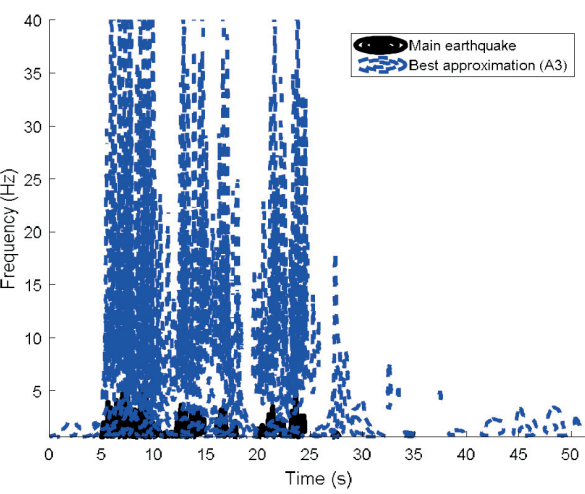

(a) Duze earthquake

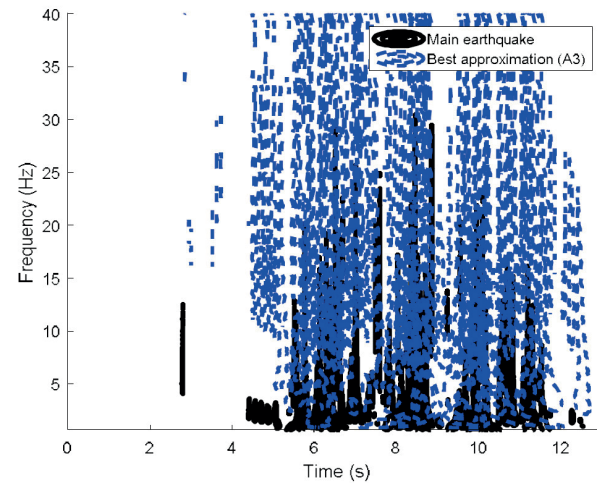

(c) Gazli earthquake

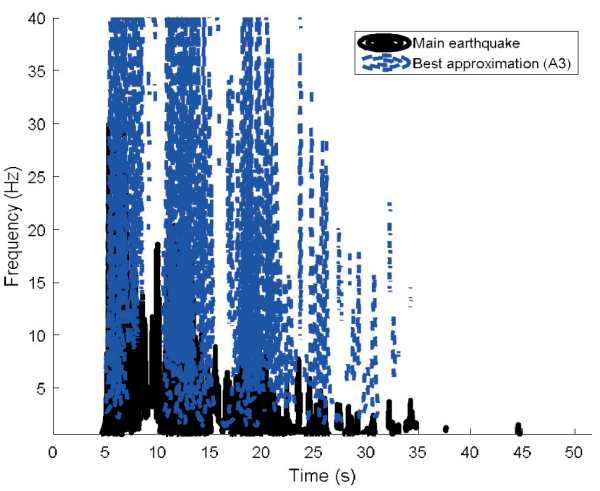

(e) Imperial Valley earthquake

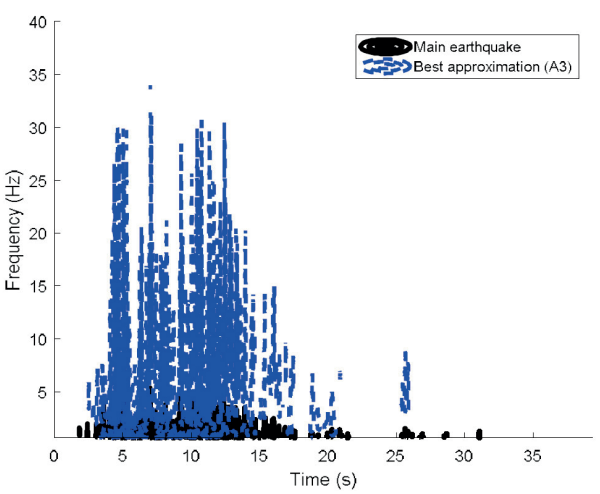

(g) Irpinia earthquake
Far-field earthquakes

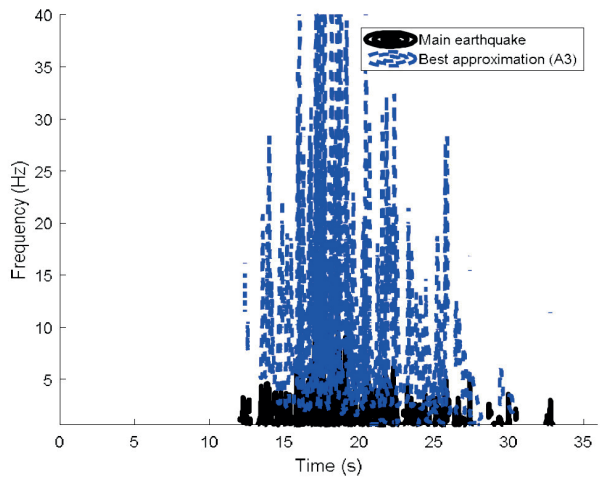

(b) Landers earthquake

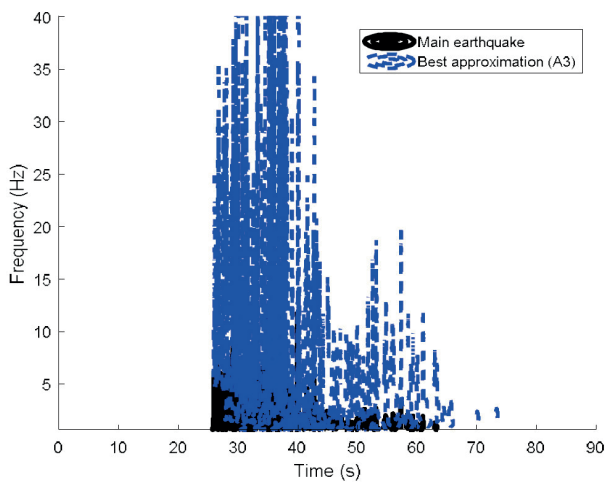

(d) Chi-Chi earthquake

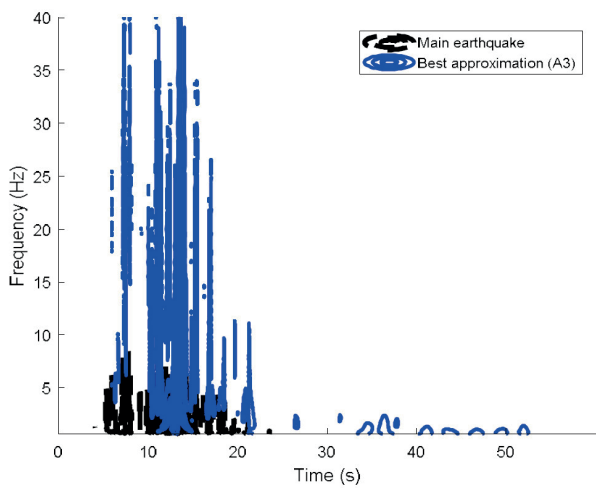

(f) Superstition earthquake

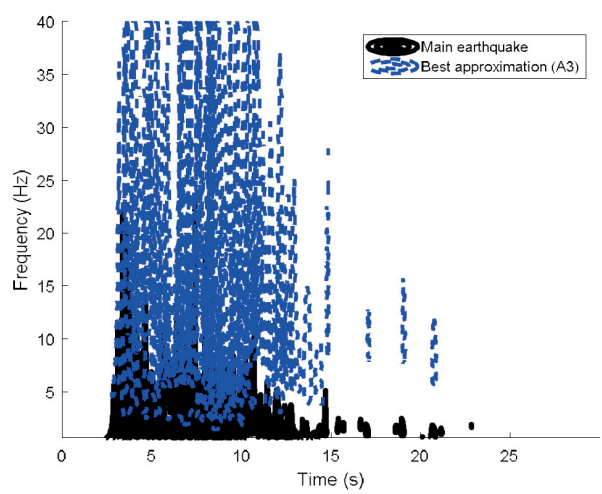

(h) Northridge earthquake

Fig. 6 Time-frequency diagram of the main earthquakes 


\section{Conclusions}

In this paper, for the first time, the discrete and continuous wavelet transform is used for nonlinear dynamic analysis of structures. In fact, since a nonlinear dynamic analysis which provides a more accurate simulation of the structural behavior against the earthquake load is time-consuming, the main aim is to reduce the computational costs using the wavelet transform. For this purpose, eight near- and far-field earthquakes are selected from FEMA P695. Each earthquake is first filtered up to 5 stages by wavelet transform. At each stage of the filter, two waves (i.e. approximation and detail) are obtained. Due to the small details in the detail wave, this wave is neglected. The next step is to study the frequency content of the earthquake using the Fourier spectrum and the continuous wavelet transform. The results show that the first five frequencies for the main earthquakes are similar

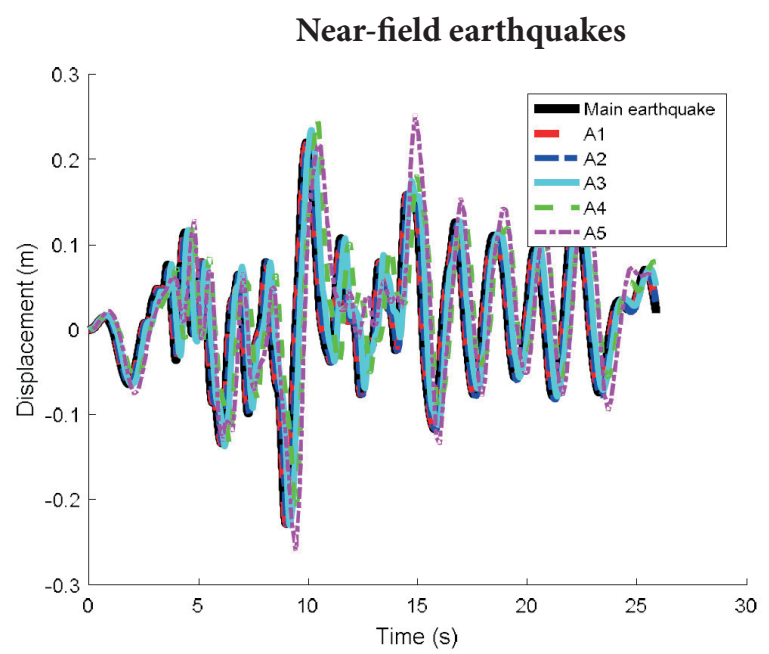

(a) Duze earthquake

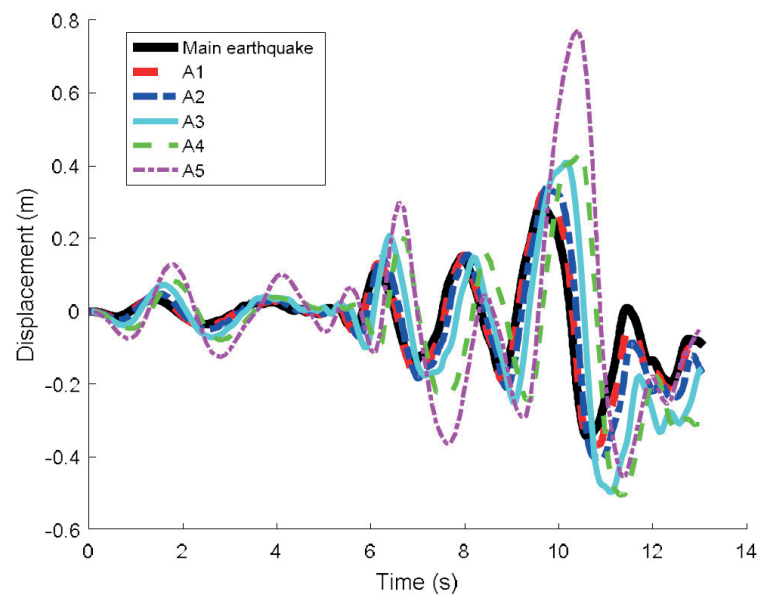

(c) Gazli earthquake

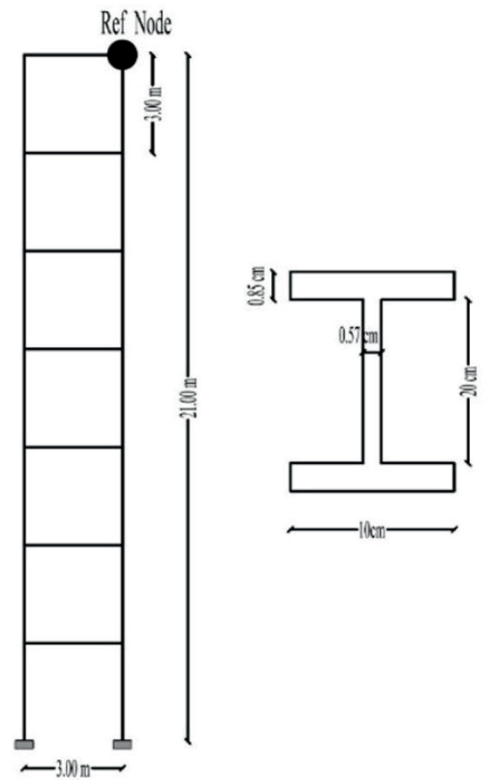

Fig. 7 The elevation of studied structure and used sections

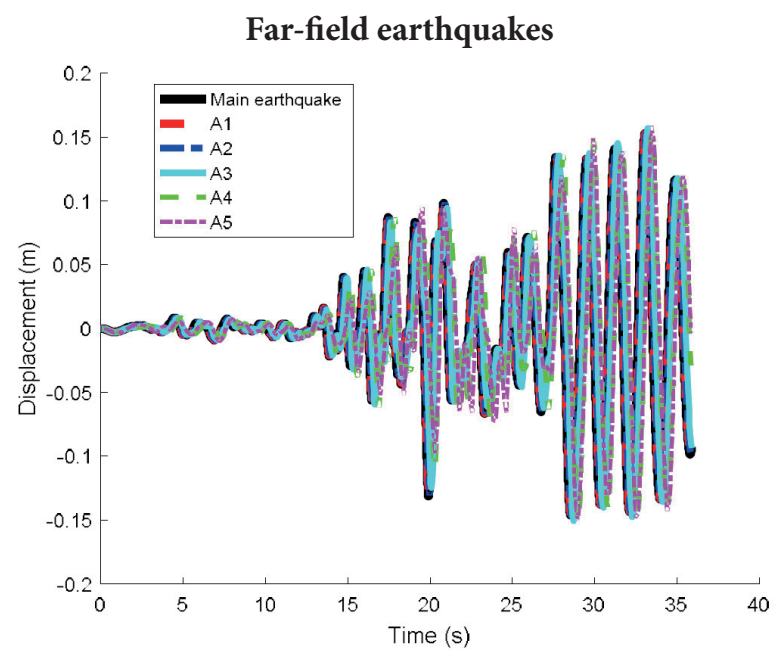

(b) Landers earthquake

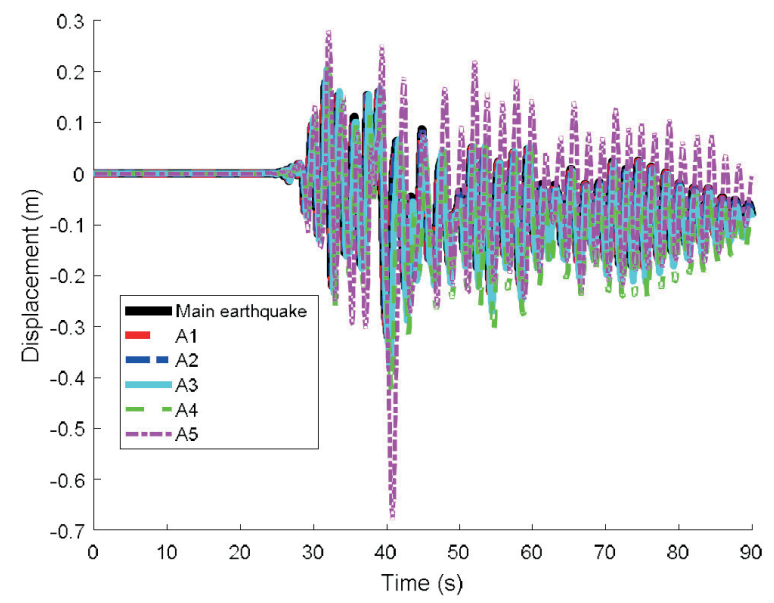

(d) Chi-Chi earthquake

Fig. 8 (a-d) Reference node displacement response for the main eathquakes 


\section{Near-field earthquakes}

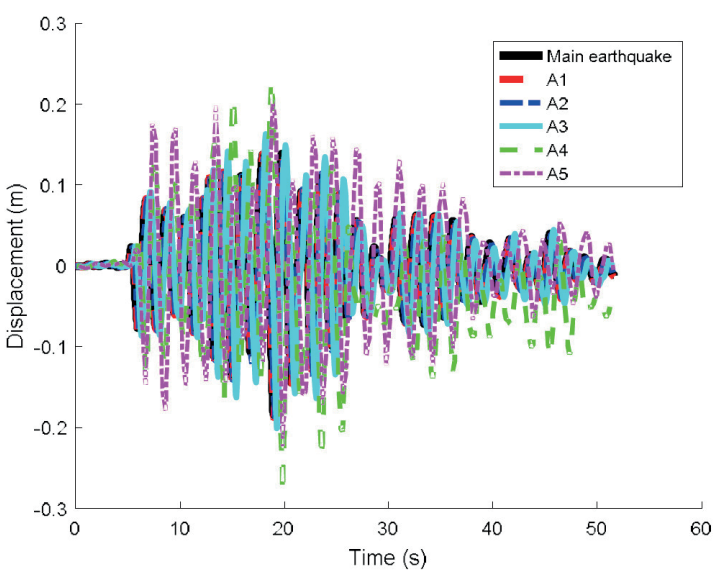

(e) Imperial Valley earthquake

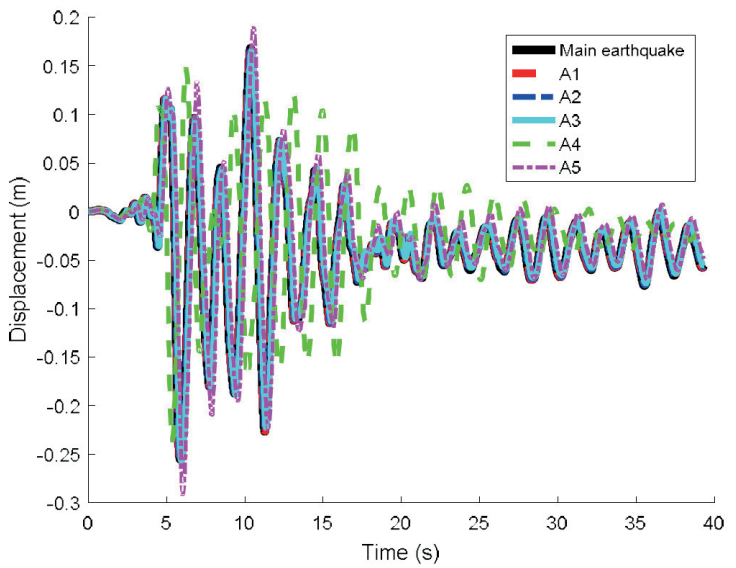

(g) Irpinia earthquake
Far-field earthquakes

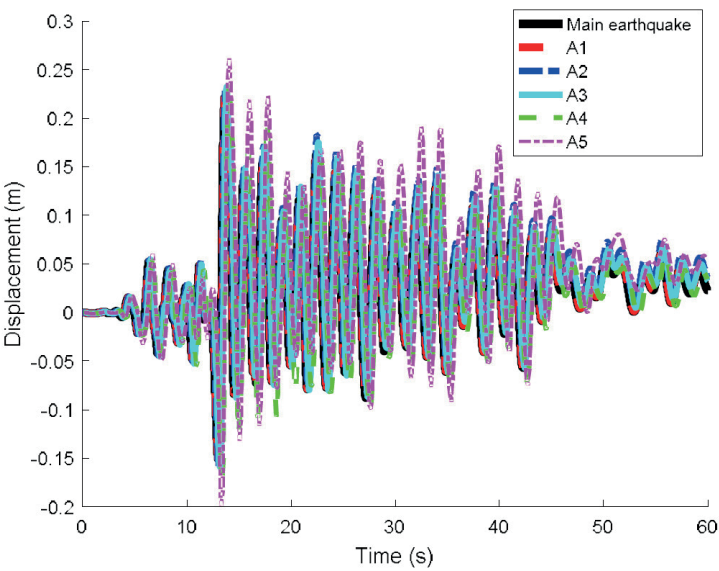

(f) Superstition earthquake

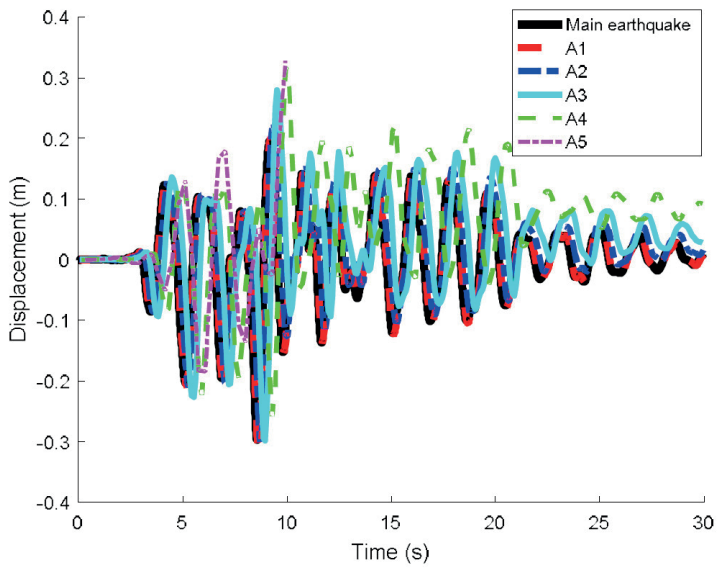

(h) Northridge earthquake

Fig. 8 (e-h) Reference node displacement response for the main eathquakes

Table 2 Maximum displacement for the reference node

\begin{tabular}{|c|c|c|c|c|c|c|c|c|}
\hline \multirow{3}{*}{ Wave } & \multicolumn{8}{|c|}{ Max displacement of the reference node $(\mathrm{cm})$} \\
\hline & \multicolumn{4}{|c|}{ Near-field } & \multicolumn{4}{|c|}{ Far-field } \\
\hline & Duze & Gazli & Imperial Valley & Irpinia & Landers & Chi-Chi & Superstition & Northridge \\
\hline Main & 22.81 & 34.40 & 18.40 & 25.53 & 15.29 & 31.91 & 22.15 & 29.70 \\
\hline$A_{1}$ & 22.87 & 37.65 & 18.94 & 25.57 & 15.32 & 32.67 & 22.16 & 30.37 \\
\hline$A_{2}$ & 22.91 & 40.28 & 18.69 & 25.58 & 15.32 & 32.80 & 23.15 & 30.26 \\
\hline$A_{3}$ & 23.47 & 49.67 & 20.06 & 25.69 & 15.70 & 38.04 & 23.23 & 29.84 \\
\hline$A_{4}$ & 24.87 & 50.56 & 27.91 & 23.74 & 15.32 & 42.58 & 23.72 & 31.71 \\
\hline$A_{5}$ & 25.98 & 77.36 & 22.36 & 29.21 & 15.86 & 67.93 & 26.22 & 32.79 \\
\hline
\end{tabular}

Table 3 The percentage error for the maximum displacement of the reference node

\begin{tabular}{|c|c|c|c|c|c|c|c|c|}
\hline \multirow{3}{*}{ Wave } & \multicolumn{8}{|c|}{ The values of error for the max displacement of the reference node $(\%)$} \\
\hline & \multicolumn{4}{|c|}{ Near-field } & \multicolumn{4}{|c|}{ Far-field } \\
\hline & Duze & Gazli & Imperial Valley & Irpinia & Landers & Chi-Chi & Superstition & Northridge \\
\hline$A_{1}$ & 0.27 & 9.45 & 2.93 & 0.15 & 0.19 & 2.38 & 0.04 & 2.25 \\
\hline$A_{2}$ & 0.42 & 17.10 & 1.55 & 0.20 & 0.15 & 2.77 & 4.48 & 1.88 \\
\hline$A_{3}$ & 2.88 & 44.39 & 9.01 & 0.62 & 2.68 & 19.19 & 4.84 & 0.44 \\
\hline$A_{4}$ & 9.00 & 46.97 & 51.64 & 7.00 & 0.15 & 33.43 & 7.08 & 6.77 \\
\hline$A_{5}$ & 13.88 & 124.91 & 21.49 & 14.43 & 3.73 & 112.85 & 18.35 & 10.40 \\
\hline
\end{tabular}


Near-field earthquakes

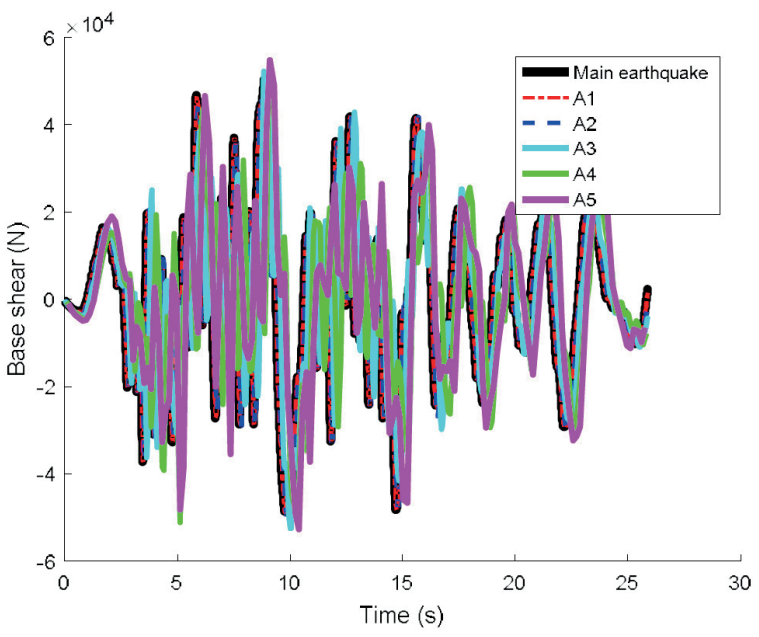

(a) Duze earthquake

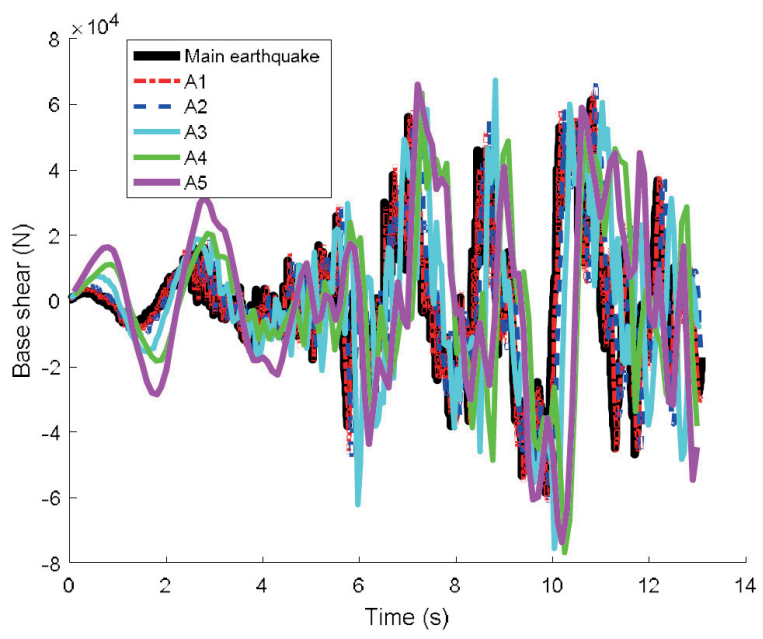

(c) Gazli earthquake

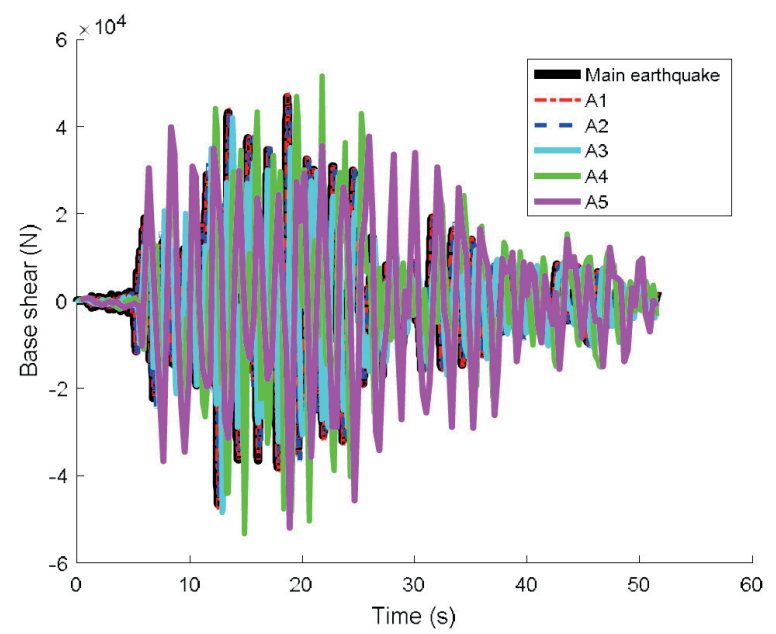

(e) Imperial Valley earthquake
Far-field earthquakes

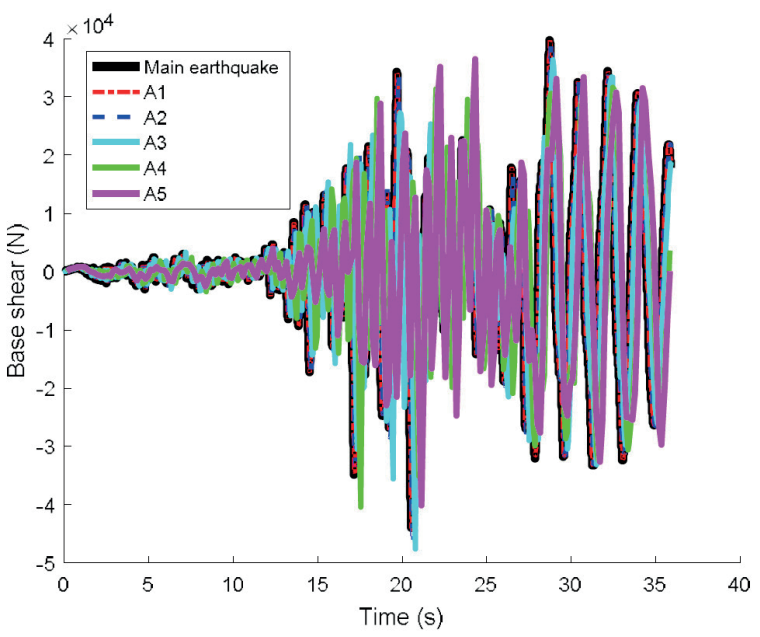

(b) Landers earthquake

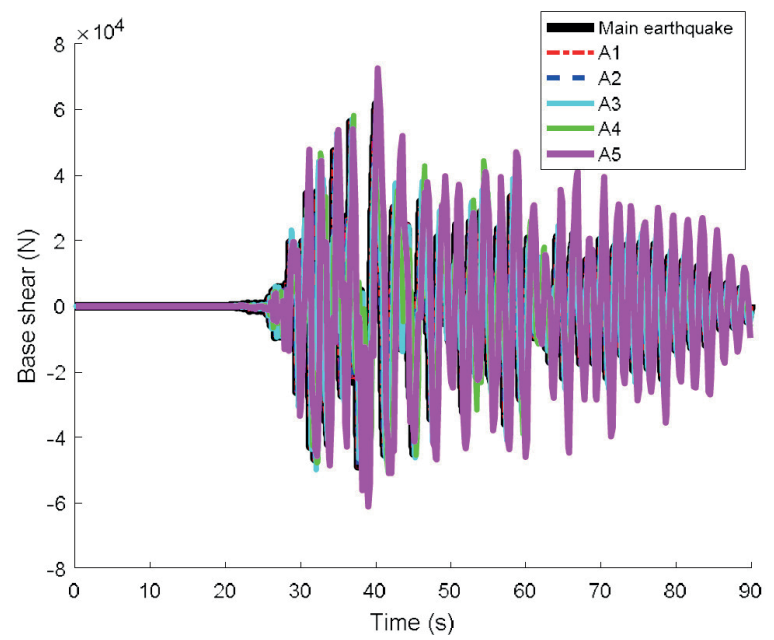

(d) Chi-Chi earthquake

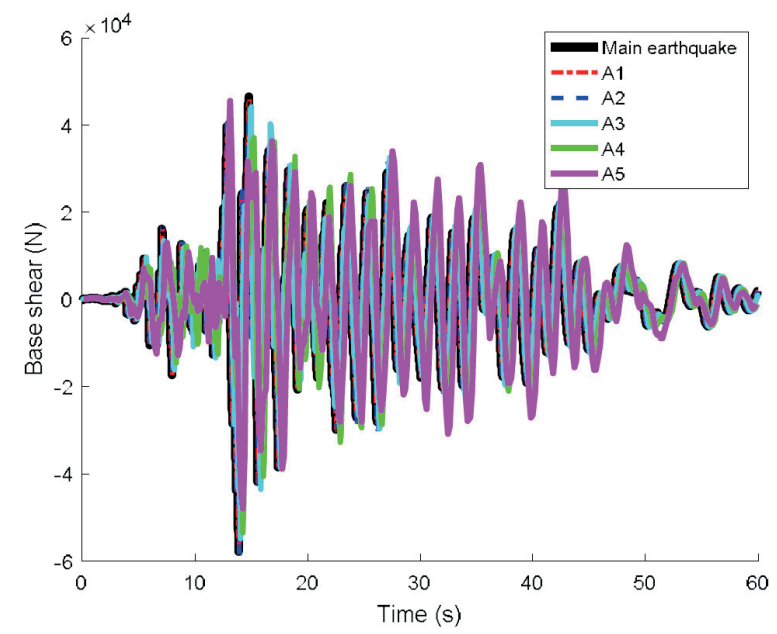

(f) Superstition earthquake

Fig. 9 (a-f) The time history of the base shear for the main earthquakes 
Near-field earthquakes

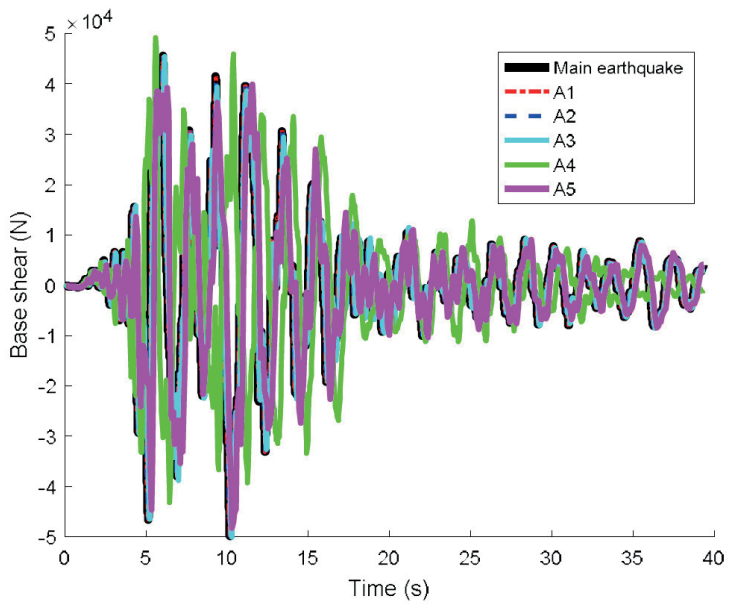

(g) Irpinia earthquake
Far-field earthquakes

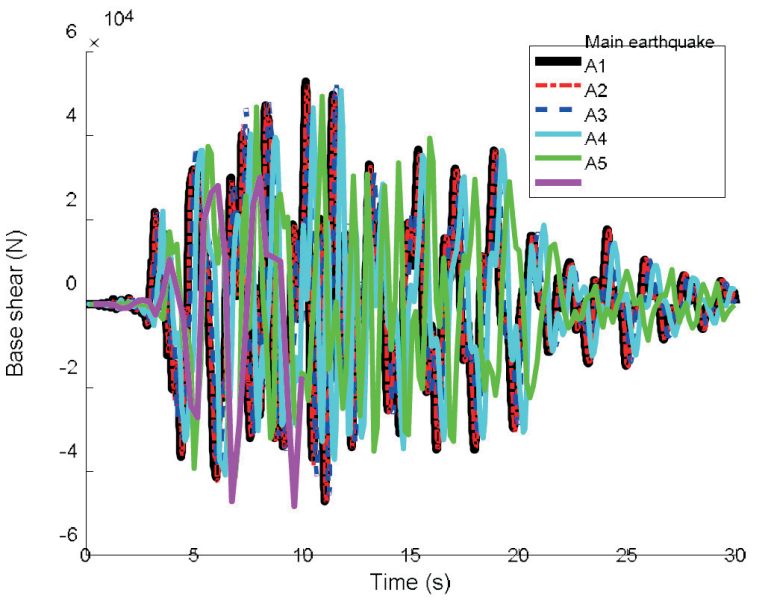

(h) Northridge earthquake

Fig. 9 (g-h) The time history of the base shear for the main earthquakes

Table 4 The maximum values of base shear for the structure subjected to the different earthquakes

\begin{tabular}{|c|c|c|c|c|c|c|c|c|}
\hline \multirow{3}{*}{ Wave } & \multicolumn{8}{|c|}{ Max base shear×104 $(\mathrm{N})$} \\
\hline & \multicolumn{4}{|c|}{ Near-field } & \multicolumn{4}{|c|}{ Far-field } \\
\hline & Duze & Gazli & Imperial Valley & Irpinia & Landers & Chi-Chi & Superstition & Northridge \\
\hline Main & 5.02 & 6.12 & 4.66 & 4.97 & 4.39 & 6.16 & 5.77 & 5.29 \\
\hline$A_{1}$ & 5.03 & 6.42 & 4.77 & 4.98 & 4.46 & 6.25 & 5.77 & 5.21 \\
\hline$A_{2}$ & 4.98 & 6.76 & 4.51 & 4.99 & 4.67 & 6.28 & 5.87 & 5.31 \\
\hline$A_{3}$ & 5.25 & 7.55 & 4.84 & 5.00 & 4.75 & 6.58 & 5.48 & 5.08 \\
\hline$A_{4}$ & 5.11 & 7.67 & 5.33 & 4.92 & 4.04 & 6.84 & 5.35 & 4.94 \\
\hline$A_{5}$ & 5.48 & 7.35 & 5.19 & 4.82 & 4.00 & 7.26 & 4.79 & 4.81 \\
\hline
\end{tabular}

Table 5 The percentage of error in the calculation of the maximum base shear for the structure subjected to the different earthquakes The error percentage for the max base shear $(\%)$

\begin{tabular}{|c|c|c|c|c|c|c|c|c|}
\hline \multirow[t]{2}{*}{ Wave } & \multicolumn{4}{|c|}{ Near-field } & \multicolumn{4}{|c|}{ Far-field } \\
\hline & Duze & Gazli & Imperial Valley & Irpinia & Landers Fema & Chi Chi & Superstition & Northridge \\
\hline$A_{1}$ & 0.19 & 4.88 & 2.43 & 0.13 & 1.42 & 1.50 & 0.00 & 1.58 \\
\hline$A_{2}$ & 0.75 & 10.49 & 3.26 & 0.35 & 6.19 & 1.88 & 1.69 & 0.43 \\
\hline$A_{3}$ & 4.52 & 23.32 & 3.93 & 0.44 & 8.06 & 6.85 & 4.97 & 4.03 \\
\hline$A_{4}$ & 1.70 & 25.29 & 14.46 & 1.15 & 7.98 & 11.00 & 7.33 & 6.60 \\
\hline$A_{5}$ & 9.10 & 20.18 & 11.41 & 3.04 & 8.91 & 17.82 & 16.98 & 8.96 \\
\hline
\end{tabular}

to those values of earthquakes obtained by wavelet transform. In addition, it is shown that using wavelet transform, the time of strong ground motion is similar to the time of dominant frequencies. At the end, the nonlinear dynamic response of a seven-story structure is studied. For this purpose, the Mallat and Shensa methods are used in the wavelet theory to analyze the dynamic response of the structure. The results showed that the analysis time is reduced about $80 \%$ while the error is about up to $6 \%$ when the main earthquake is decomposed by wavelet transform and the approximate waves are used in the nonlinear dynamic analysis. 
Near-field earthquakes

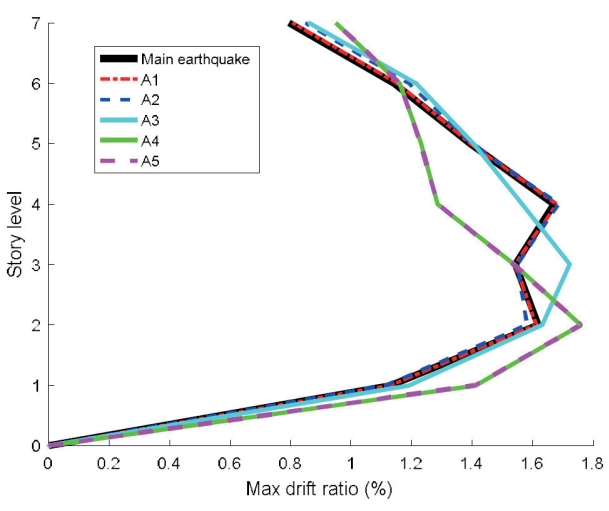

(a) Duze earthquake

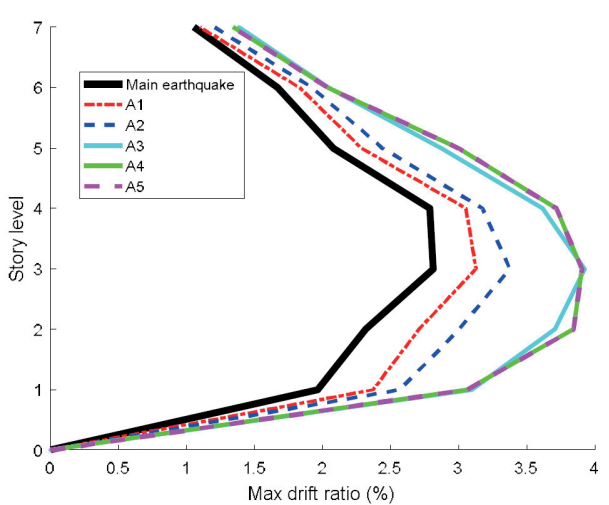

(c) Gazli earthquake

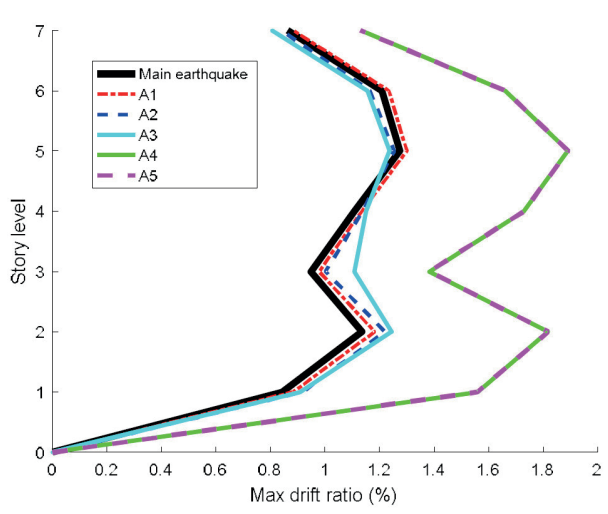

(e) Imperial Valley earthquake

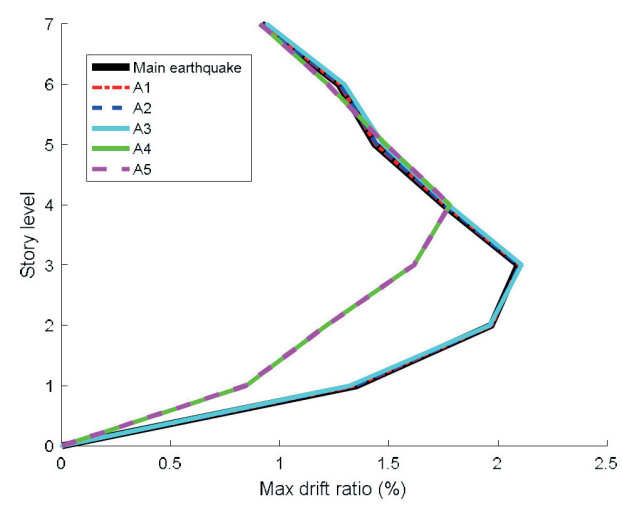

(g) Irpinia earthquake
Far-field earthquakes

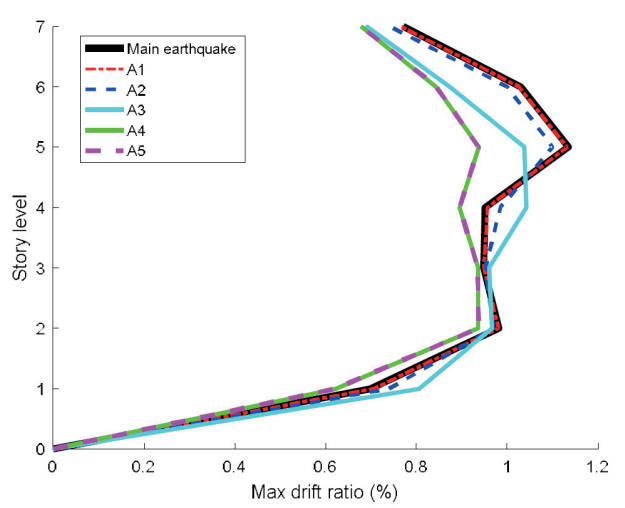

(b) Landers earthquake

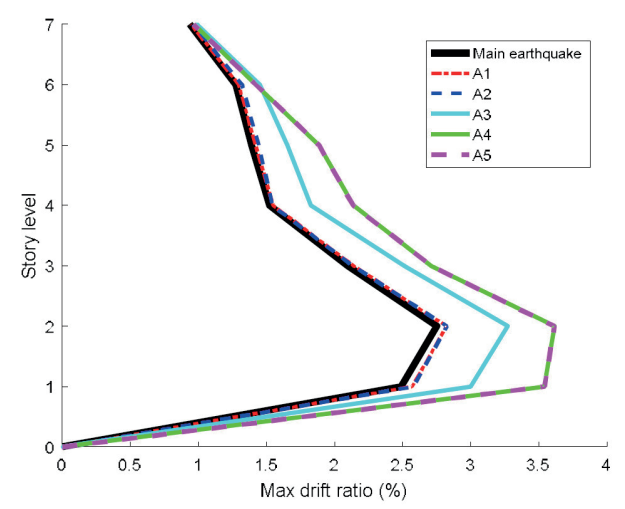

(d) Chi-Chi earthquake

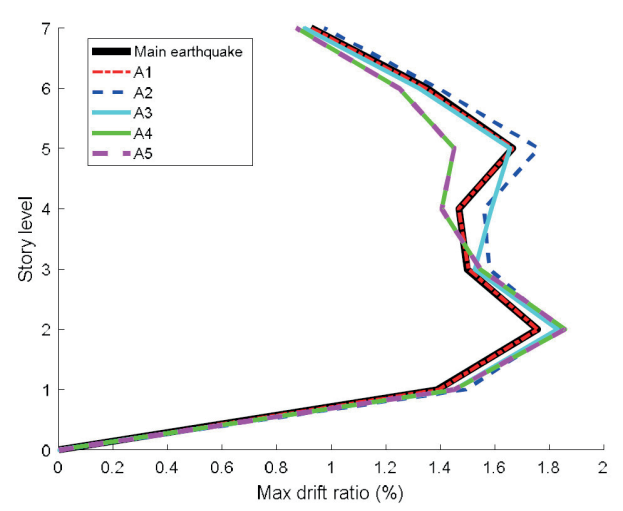

(f) Superstition earthquake

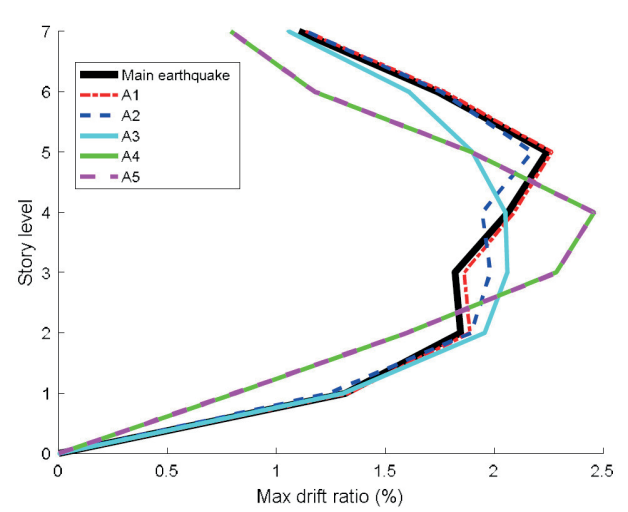

(h) Northridge earthquake

Fig. 10 Base shear curve for the main earthquakes 


\section{References}

[1] Tavakoli, R., Kamgar, R., Rahgozar, R. "The Best Location of Belt Truss System in Tall Buildings Using Multiple Criteria Subjected to Blast Loading", Civil Engineering Journal, 4(6), pp. 1338-1353, 2018.

https://doi.org/10.28991/cej-0309177

[2] Kamgar, R., Rahgozar, R. "A simple method for determining the response of linear dynamic systems", Asian Journal of Civil Engineering, 17(5), pp. 785-801, 2016.

[3] Kamgar, R., Khatibinia, M., Khatibinia, M. "Optimization criteria for design of tuned mass dampers including soil-structure interaction effect", International Journal of Optimization in Civil Engineering, 9(2), pp. 213-232, 2019.

[4] Kamgar, R., Rahgozar, R. "Determination of critical excitation in seismic analysis of structures", Earthquakes and Structures, 9(4), pp. 875-891, 2015.

https://doi.org/10.12989/eas.2015.9.4.875

[5] Tavakoli, R., Kamgar, R., Rahgozar, R. "Seismic performance of outrigger-belt truss system considering soil-structure interaction", International Journal of Advanced Structural Engineering, 11(1), pp. $45-54,2019$.

https://doi.org/10.1007/s40091-019-0215-7

[6] Kamgar, R., Shojaee, S., Rahgozar, R. "Rehabilitation of tall buildings by active control system subjected to critical seismic excitation", Asian Journal of Civil Engineering, 16(6), pp. 819-833, 2015.

[7] Heidari, A., Rahgozar, R., Kamgar, R. "Free vibration analysis of tall building with geometrical discontinuites", Asian Journal of Civil Engineering, 15(1), pp. 107-122, 2014.

[8] Kamgar, R., Samea, P., Khatibinia, M. "Optimizing parameters of tuned mass damper subjected to critical earthquake", The Structural Design of Tall and Special Buildings, 27(7), Article ID e1460, 2018. https://doi.org/10.1002/tal.1460

[9] Khatibinia, M., Gholami, H., Kamgar, R. "Optimal design of tuned mass dampers subjected to continuous stationary critical excitation", International Journal of Dynamics and Control, 6(3), pp. 1094-1104, 2018. https://doi.org/10.1007/s40435-017-0386-7

[10] Dadkhah, M., Kamgar, R., Heidarzadeh, H. "Reducing the Cost of Calculations for Incremental Dynamic Analysis of Building Structures Using the Discrete Wavelet Transform", Journal of Earthquake Engineering, 2020. https://doi.org/10.1080/13632469.2020.1798830

[11] Lu, X., Xie, L., Guan, H., Huang, Y., Lu, X. "A shear wall element for nonlinear seismic analysis of super-tall buildings using OpenSees", Finite Elements in Analysis and Design, 98, pp. 14-25, 2015 .

https://doi.org/10.1016/j.finel.2015.01.006

[12] Walter, G. G., Shen, X. "Wavelets and Other Orthogonal Systems", 2nd ed., CRC press, Boca Raton, FL, USA, 2018. https://doi.org/10.1201/9781315273716

[13] Kaveh, A., Mahdavi, V. R. "Modification of ground motions using wavelet transform and VPS algorithm", Earthquakes and Structures, 12(4), pp. 389-395, 2017. https://doi.org/10.12989/eas.2017.12.4.389
[14] Salajegheh, E., Heidari, A. "Optimum design of structures against earthquake by adaptive genetic algorithm using wavelet networks", Structural and Multidisciplinary Optimization, 28(4), pp. 277-285, 2004.

https://doi.org/10.1007/s00158-004-0422-z

[15] Heidari, A., Majidi, N. "Earthquake acceleration analysis using wavelet method", Earthquake Engineering and Engineering Vibration, (Accepted for publication March 2019) (in press)

[16] Heidari, A., Salajegheh, E. "Time history analysis of structures for earthquake loading by wavelet networks", Asian Journal of Civil Engineering, 7(2), pp. 155-168, 2006.

[17] Heidari, A., Salajegheh, E. "Approximate dynamic analysis of structures for earthquake loading using FWT", International Journal of Engineering, Transactions B: Applications, 20(1), pp. 37-47, 2007.

[18] Heidari, A., Raeisi, J., Kamgar, R. "Application of wavelet theory in determining of strong ground motion parameters", International Journal of Optimization in Civil Engineering, 8(1), pp. 103-115, 2018.

[19] Heidari, A., Raeisi, J., Kamgar, R. "The application of wavelet theory with denoising to estimate the parameters of earthquake", Scientia Iranica, International Journal of Science and Technology, (Accepted for publication April 2019) (in press) https://doi.org/10.24200/sci.2019.50675.1815

[20] Heidari, A. "Optimum Design of Structures for Earthquake Induced Loading by Genetic Algorithm Using Wavelet Transform", Advances in Applied Mathematics and Mechanics, 2(1), pp. 107-117, 2010. https://doi.org/10.4208/aamm.09-m0932

[21] Heidari, A., Pahlavan Sadegh, S., Raeisi, J. "Investigating the Effect of Soil Type on Non-linear Response Spectrum Using Wavelet Theory", International Journal of Civil Engineering, 17, pp. 1909-1918, 2019.

https://doi.org/10.1007/s40999-019-00394-6

[22] Gholizadeh, S., Samavati, O. A. "Structural optimization by wavelet transforms and neural networks", Applied Mathematical Modelling, 35(2), pp. 915-929, 2011.

https://doi.org/10.1016/j.apm.2010.07.046

[23] Jiang, X., Adeli, H. "Dynamic fuzzy wavelet neuroemulator for non-linear control of irregular building structures", International Journal for Numerical Methods in Engineering, 74(7), pp. 10451066, 2008.

https://doi.org/10.1002/nme.2195

[24] Blachowski, B., Pnevmatikos, N. "Neural Network Based Vibration Control of Seismically Excited Civil Structures", Periodica Polytechnica Civil Engineering, 62(3), pp. 620-628, 2018. https://doi.org/10.3311/PPci.11601

[25] FEMA "Quantification of Building Seismic Performance Factors", [pdf] Federal Emergency Management Agency, Washington, DC, USA, Rep. FEMA-P695, 2009. Available at: https:/www.fema.gov/ media-library-data/20130726-1716-25045-9655/fema_p695.pdf

[26] Daubechies, I. (ed.) "Proceedings of Symposia in Applied Mathematics, Different Perspectives on Wavelets", Vol. 47, American Mathematical Society, Providence, RI, USA, 2016. 
[27] Basu, B., Gupta, V. K. "Seismic Response of SDOF Systems by Wavelet Modeling of Nonstationary Processes", Journal of Engineering Mechanics, 124(10), pp. 1142-1150, 1998. https://doi.org/10.1061/(ASCE)0733-9399(1998)124:10(1142)

[28] Suárez, L. E., Montejo, L. A. "Generation of artificial earthquakes via the wavelet transform", International Journal of Solids and Structures, 42(21-22), pp. 5905-5919, 2005. https://doi.org/10.1016/j.ijsolstr.2005.03.025

[29] Salajegheh, E., Heidari, A. "Time history dynamic analysis of structures using filter banks and wavelet transforms", Computers and Structures, 83(1), pp. 53-68, 2005.

https://doi.org/10.1016/j.compstruc.2004.08.008

[30] Rioul, O., Duhamel, P. "Fast algorithms for discrete and continuous wavelet transforms", IEEE Transactions on Information Theory, 38(2), pp. 569-586, 1992.

https://doi.org/10.1109/18.119724

[31] Bose, N. K. "Applied Multidimensional Systems Theory", 2nd ed., Springer, Cham, Switzerland, 2017. https://doi.org/10.1007/978-3-319-46825-9

[32] Mallat, S. G. "A theory for multiresolution signal decomposition: the wavelet representation", IEEE Transactions on Pattern Analysis and Machine Intelligence, 11(7), pp. 674-693, 1989.

https://doi.org/10.1109/34.192463
[33] Sundararajan, D. "Discrete Wavelet Transform: A Signal Processing Approach", John Wiley and Sons, Hoboken, NJ, USA, 2016.

[34] Chopra, A. K. "Dynamics of Structures: Theory and Applications to Earthquake Engineering", 5th ed., Pearson, Hoboken, NJ, USA, 2017.

[35] Mazzoni, S., McKenna, F., Scott, M. H., Fenves, G. L. "OpenSees command language manual", Pacific Earthquake Engineering Research (PEER) Center, University of California, Berkeley, CA, USA, 2006.

[36] Chandler, A. M., Pappin, J. W., Coburn, A. W. "Vulnerability and seismic risk assessment of buildings following the 1989 Newcastle, Australia earthquake", Bulletin of the New Zealand National Society for Earthquake Engineering, 24(2), pp. 116-138, 1991. https://doi.org/10.5459/bnzsee.24.2.116-138

[37] Gholizadeh, S., Salajegheh, E. "Optimal seismic design of steel structures by an efficient soft computing based algorithm", Journal of Constructional Steel Research, 66(1), pp. 85-95, 2010. https://doi.org/10.1016/j.jcsr.2009.07.006 